\title{
WORKSHOP TO REVIEW \\ PROBLEM-BEHAVIOR RESEARCH PROGRAMS: \\ PEDESTRIAN, BICYCLE, AND \\ PUPIL TRANSPORTATION SAFETY
}

Mary E. Marks

John W. McNair

Ralph K. Jones

Kent B. Joscelyn

The University of Michigan

Highway Safety Research Institute

Ann Arbor, Michigan 48109

September 1981

Prepared for

U.S. Department of Transportation

National Highway Traffic Safety Administration

Washington, D.C. 20590

Contract No. DOT-HS-8-02031 



\author{
WORKSHOP TO REVIEW \\ PROBLEM-BEHAVIOR RESEARCH PROGRAMS: \\ PEDESTRIAN, BICYCLE, AND \\ PUPIL TRANSPORTATION SAFETY
}

Mary E. Marks

John W. MeNair

Ralph K. Jones

Kent B. Joscelyn

The University of Michigan

Highway Safety Research Institute

Ann Arbor, Michigan 48109

September 1981

Prepared for

U.S. Department of Transportation

National Highway Traffic Safety Administration

Washington, D.C. 20590

Contract No. DOT-HS-8-02031

The contents of this report reflect the views of the authors, who are responsible for the facts and accuracy of the data presented herein. The contents do not necessarily reflect the official views or policy of the Department of Transportation. This report does not constitute a standard, specification, or regulation.

This document is disseminated under the sponsorship of the Department of Transportation in the interest of information exchange. The United States Government assumes no liability for its contents or use thereof.

The United States Government does not endorse products or manufacturers. Trade or manufacturer's names appear herein solely because they are considered essential to the objectives of this report.

Document is available to the public through

the National Technical Information Service

Springfield, Virginia 22161 


\section{ACKNOWLEDGMENT}

This report is a result of the efforts of many persons and stems from their able and varied contributions. We thank all who assisted in its development, preparation, and production.

Special recognition is due to those who participated in the workshop and whose expert contributions formed the basis for the report. All gave generously of their time, energy, and knowledge. Their willing support has made this report possible. The participants and their affiliations are listed in Appendix $D$.

We also acknowledge the staff of The Capitol Hilton Conference Center, and in particular Ms. Yvonne Kowal who facilitated the planning and arranging of this workshop.

This report was drafted primarily by Mary E. Marks and John W. McNair from notes and records of the workshop sessions. Other HSRI personnel also made important contributions. The report was edited by James E. Haney. Anne L. VanDerworp served as production editor and produced the report.

We thank all who contributed.

Mary E. Marks

Principal Investigator
Ralph K. Jones

Principal Investigator
Kent B. Joscelyn

Principal Investigator 

WORKSHOP TO REVIEW PROBLEM-BEHAVIOR RESEARCH PROGRAMS: WORKSHOP ON PEDESTRIAN, BICYCLE, AND PUPIL TRANSPORTATION SAFETY

\section{SUMMARY}

A workshop was held on 27-28 October 1980 at The Capitol Hilton, Washington, D.C. The workshop was one of a series conducted by The University of Michigan Highway Safety Research Institute under the sponsorship of the U.S. Department of Transportation, National Highway Traffic Safety Administration (NHTSA) contract no. DOT-HS-8-02031, entitled "Workshop to Review Problem-Behavior Research Programs."

The workshop approach was designed to permit an in-depth review of specific program elements in the Pedestrian, Bicycle, and Pupil Transportation Safety program area. Research, development, and demonstration projects were all considered. Participants were selected and assigned to two working groups by NHTSA. These groups participated in a series that dealt with the following topics:

- Research and Development Projects;

- Traffic Safety Programs Projects; and

- Technology Transfer.

Participants were asked to focus upon the relevancy, necessity, and sufficiency of the various projects in achieving overall safety goals.

Background material was provided to participants by NHTSA at the workshop. Plenary sessions were held during which NHTSA staff described the objectives and the program efforts within the Research and Development, Traffic Safety Programs, and Technology Transfer areas. These presentations were intended to serve as the frame of reference for the workshop. Participants were also provided with summaries of project descriptions in each of these three areas.

Discussions of the workshop are summarized below. 


\section{RESEARCH AND DEVELOPMENT PROJECTS}

The workshop participants generally supported the relevancy and necessity of the proposed Research and Development (R\&D) projects where adequate background information was available. (It should be noted that many of the proposed projects were dependent upon the results of ongoing research efforts.) Concerns were directed at the sufficiency of the projects' methods for accomplishing stated objectives. Clearer delineation of the focus of projects (i.e., target groups, strategies for testing, methods) was recommended.

NHTSA was urged by the workshop group to take a broader approach to the pedestrian, bicycle, and pupil transportation safety problem. Participants recommended extending the scope of countermeasure activity beyond public information and education (PI\&E) campaigns. Greater attention to enforcement activity and highway/environmental design solutions was suggested. While participants recognized that the latter area was not within the purview of NHTSA per se, they did recommend that NHTSA interact with other agencies to a greater extent to treat the problem as a whole. Accordingly, the group strongly endorsed the concept of interageney exchange of information and urged NHTSA to take the lead in sponsoring a mechanism for coordinating efforts with other federal agencies.

\section{TRAFFIC SAFETY PROGRAMS PROJECTS}

The projects proposed by Traffic Safety Programs (TSP) were viewed as both relevant and necessary by the workshop participants. The sufficiency of the projects' methods for accomplishing the stated objectives was, for the most part, considered appropriate. Participants did, however, ask for clarification of the mechanics of obtaining support under the project entitled "Countermeasure Support and Implementation." NHTSA was urged to clearly specify how funds will be administered under that contract before it is implemented.

More general concern was expressed about the lack of criteria for countermeasure implementation. Participants noted that no specified 
criteria for releasing a countermeasure exist. The panel recommended that NHTSA establish such criteria to determine at what point countermeasures should be transferred to the states.

\section{TECHNOLOGY TRANSFER}

Technology transfer efforts were viewed as extremely relevant and necessary by the workshop. Questions about the sufficiency of the activity were raised. Two points were addressed by the panel:

- the ability to capture information, and

- the ability to make information available to potential users.

The panel members saw a need for a system to identify, collect, and index information and urged NHTSA to establish such a structured system. The inclusion of information being produced under state, local, and private sponsorship as well as that produced under NHTSA sponsorship was recommended.

The second aspect of the technology transfer problem addressed by the panel was making information available once it was captured. Participants outlined three steps in this process:

- identifying potential users,

- identifying the users' needs, and

- identifying potential delivery systems.

Concern was expressed that information is not getting to the people who need it. The identification of potential users was seen as the essential first step in this process.

The need for a systematic and continuous system of delivery of information was strongly emphasized by panel members. The workshop recommended that NHTSA establish a clearinghouse to gather and disseminate information on a routine basis. Greater use of existing networks (e.g., PTAs, community and professional organizations) in the dissemination process was also recommended. 

Tochaical Report Documontation Poge

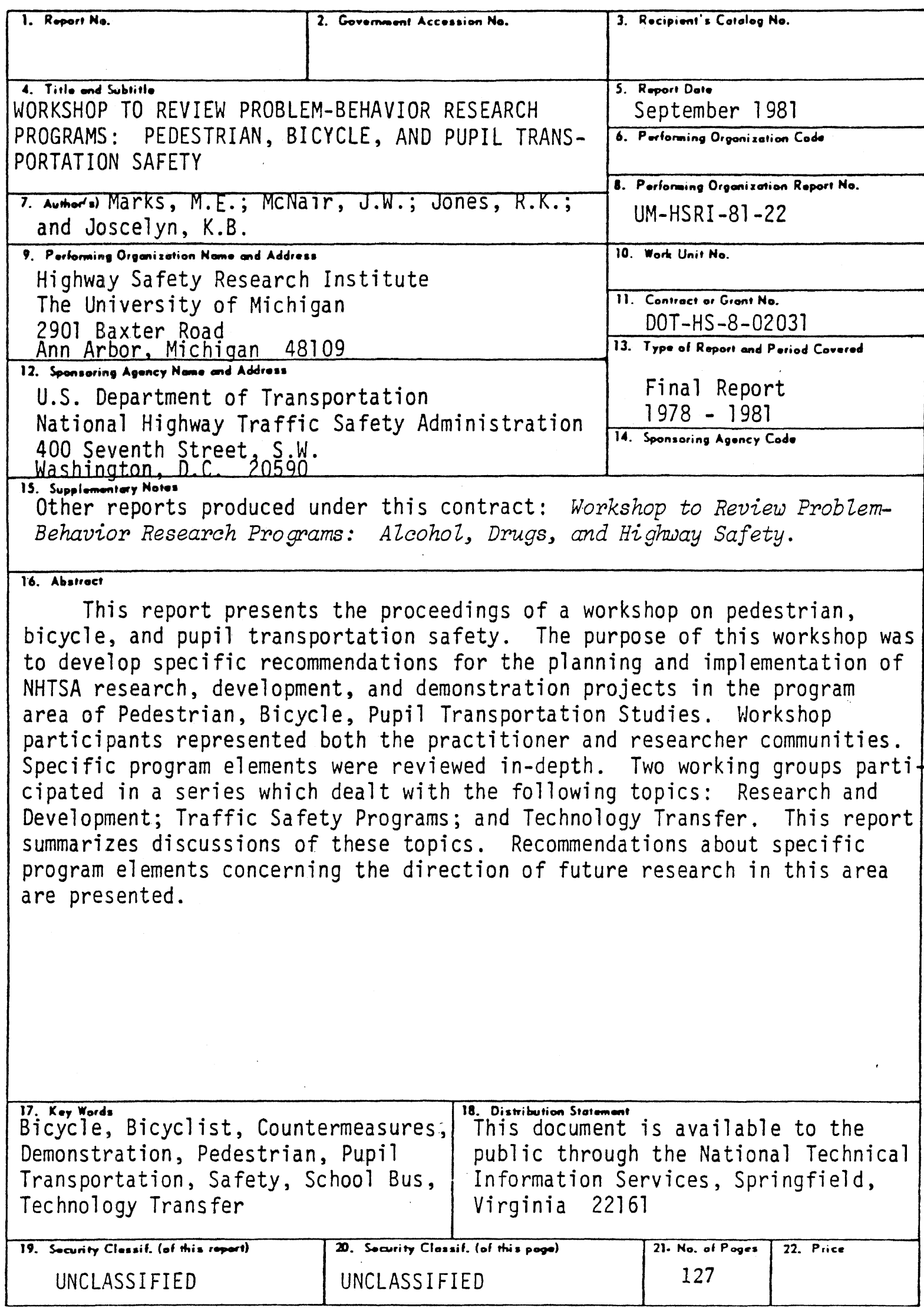



CONTENTS

1.0 INTRODUCTION 1

1.1 Background 1

1.2 The Purpose of Workshop II, Pedestrian, Bicycle, and

Pupil Transportation Safety 2

1.3 Scope of Report 3

2.0 OVERVIEW OF THE PEDESTRIAN, BICYCLE, AND PUPIL

TRANSPORTATION PROGRAM 5

2.1 Objectives and Priority of the Proposed 403 Pedestrian,

Bicycle, and Pupil Transportation Program 5

2.2 Overview of $R \& D$ Activity 7

$\begin{array}{lll}\text { 2.2.1 Pedestrian Safety } & 7\end{array}$

2.2.2 Bicycle Safety 11

2.2.3 Pupil Transportation Safety 11

2.3 Overview of TSP Activity 14

2.3.1 Pedestrian Safety 14

$\begin{array}{lll}2.3 .2 & \text { Bicycle Safety } & 15\end{array}$

2.3.3 Pupil Transportation Safety . 16

$\begin{array}{ll}2.4 \text { Summary } & 17\end{array}$

3.0 RESEARCH AND DEVELOPMENT 19

$\begin{array}{lll}3.1 \text { Background } & 19\end{array}$

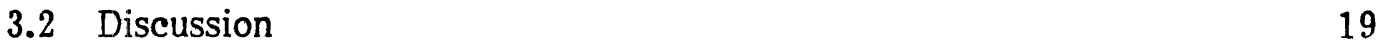

3.2.1 General Comments 20

3.2.2 Project-Specific Comments 22

3.2.2.1 Transportation of the Handicapped

(Project \#35) 22

3.2.2.2 Development and Test of Right-Turn-On-Red

(RTOR) Countermeasures (Project \#36) 26

3.2.2.3 Field Test of Urban and Rural Pedestrian

Safety Messages (Project \#37) 29

3.2.2.4 Field Test of Selected Conspicuity Countermeasures for Pedestrians and Bicyclists 
(Project \#38)

3.2.2.5 Identification and Test of Countermeasures for Elderly/Handicapped Pedestrians (Project \#39)

3.2.2.6 Pedestrian/Bicyclist/Pupil Transportation

Program Review Workshop (Project \#40)

3.2.2.7 Pedestrian State-of-the-Art Safety Literature

Review

3.2.2.8 Development and Field Test of Public

Information and Education Safety Messages

(Project \#42)

3.2.2.9 School-Bus-Related Countermeasure Review and Update (Project \#43)

3.3 Additional Research and Development Topics 50

$\begin{array}{lll}3.4 \text { Summary } & 51\end{array}$

4.0 TRAFFIC SAFETY PROGRAMS 53

4.1 Background 53

4.2 Discussion 53

4.2.1 General Comments 53

4.2.2 Project-Specific Comments 55

4.2.2.1 Countermeasure Support and Implementation (Project \#1) 55

4.2.2.2 Child Traffic Safety Club Demonstration 59

$\begin{array}{lll}4.3 & \text { Additional TSP Topies . } & 61\end{array}$

$\begin{array}{lll}4.4 & \text { Summary } & 61\end{array}$

5.0 TECHNOLOGY TRANSFER 63

5.1 Background 63

5.2 Discussion $\quad 63$

5.2.1 General Comments 64

5.2.2 Project-Specific Comments 68

5.3 Additional Technology Transfer Topics 72

$\begin{array}{lll}5.4 & \text { Summary } & 72\end{array}$

6.0 CONCLUSIONS AND RECOMMENDATIONS 73

$\begin{array}{ll}\text { 6.1 Research and Development Projects } & 73\end{array}$ 
6.2 Traffic Safety Programs Projects

$\begin{array}{lll}6.3 & \text { Technology Transfer } & 75\end{array}$

APPENDIX A - RESEARCH AND DEVELOPMENT 81

$\begin{array}{ll}\text { APPENDIX B - TRAFFIC SAFETY PROGRAMS } & 101\end{array}$

APPENDIX C - PEDESTRIAN ACCIDENT INFORMATION 111

$\begin{array}{ll}\text { APPENDIX D - LIST OF WORKSHOP PARTICIPANTS } & 117\end{array}$

$\begin{array}{ll}\text { BIBLIOGRAPHY } & 127\end{array}$ 
$$
\text { , }
$$ 


\subsection{INTRODUCTION}

This report presents the findings of a workshop that reviewed research, development, and demonstration needs in the area of pedestrian, bicycle, and pupil transportation safety. The workshop was held on 27-28 October 1980 at The Capitol Hilton, Washington, D.C. The workshop was one of a series conducted by the Policy Analysis Division of The University of Michigan, Highway Safety Research Institute, under the sponsorship of the U.S. Department of Transportation, National Highway Traffic Safety Administration contract no. DOT-HS-8-02031.

\subsection{Background}

In September 1978, HSRI received the contract entitled "Workshop to Review Problem-Behavior Research Programs" from the National Highway Traffic Safety Administration (NHTSA). Its general objective is to provide information from researchers and practitioners that will assist NHTSA in developing specific research programs to address current needs. This effort is part of NHTSA's plan to conduct periodic conferences to review technical developments, new information, and changing state and local needs in terms of traffic safety priorities. The program areas addressed by this contract are:

- Alcohol and Drugs;

- Pedestrian, Bicycle, and Pupil Transportation Studies; and

- Safe Driving Conformance.

During this same time period, NHTSA announced its first public plan describing research, development, and demonstration activities to be conducted under funds provided by Section 403 of the Highway Safety Act of 1966 (23 USC 403). That plan covered the Fiscal Year 1980-1984 time period. After it was announced, the Transportation Research Board (TRB) 
of the National Academy of Sciences (NAS) was asked to convene a general meeting of the scientific and practitioner communities to provide comment on the plan. A legal docket was also opened by NHTSA for other public comment.

As a follow-up to these activities the workshops to be conducted under the Problem-Behavior contract were enlarged from six to ten outside participants to thirty outside participants to discuss in greater detail specific program areas. The objectives of the Problem-Behavior Workshops are two-fold. The first of these is to identify program areas and projects that should be undertaken by NHTSA. The second objective is to provide NHTSA with as much project-specific comment as possible with regard to:

- technical content;

- estimate of schedules; and where appropriate

- suggestions for funding or level of effort needed to undertake a project in a satisfactory manner.

\subsection{The Purpose of Workshop II, Pedestrian, Bicycle, and Pupil}

\section{Transportation Safety}

The purpose of this workshop was to develop specific recommendations for the planning and implementation of NHTSA research, development, and demonstration projects in the Pedestrian, Bicycle, and Pupil Transportation Program Area. Project priority, design and method, scheduling, and cost were to be considered.

The workshop approach was designed (1) to provide the opportunity to discuss and comment on important issues in the areas of pedestrian, bicycle, and pupil transportation safety, and (2) to permit an in-depth review of specific program elements. Emphasis was placed on small-group working sessions. Participants were selected and divided into two groups of approximately fifteen people by NHTSA. Two NHTSA staff members were available to each group as resource people: one from Traffic Safety Programs, and one from Research and Development. HSRI staff members were assigned to each group to aid in moderating and recording. 
A total of three small-group working sessions were held during the workshop. Topics include:

- Research and Development Projects;

- Traffic Safety Programs Projects; and

- Technology Transfer.

During each working session, participants were asked to focus upon the relevancy, necessity, and sufficiency of the various projects in achieving overall safety goals.

Background material was provided to participants by NHTSA at the workshop. Plenary sessions were held during which NHTSA staff described the objectives and the program efforts within the Research and Development (R\&D), Traffic Safety Programs (TSP), and Technology Transfer areas. These presentations were to serve as the frame of reference for the workshop discussions. Participants were also provided with summaries of project descriptions in each of these three areas.

\subsection{Scope of Report}

This report has six chapters. The five that follow are briefly described below.

Chapter Two, Overview of the Pedestrian, Bicycle, and Pupil Transportation Program, summarizes the focus of NHTSA's Research and Development $(R \& D)$ and Traffic Safety Programs activities within this program area.

Chapter Three, Research and Development, presents the discussion of projects having as their focus fundamental research and evaluation efforts.

Chapter Four, Traffic Safety Programs, focuses on projects comprising efforts related to assistance in meeting 402 goals. The concerns and recommendations of the panel are summarized.

Chapter Five, Knowledge Transfer, presents the discussion concerned with dissemination of research products for use by practitioners and researchers.

Chapter Six synthesizes the conclusions and recommendations of the panel. 
Presentations by the NHTSA representatives for $R \& D$ and TSP can be found in Appendices $A$ and $B$, respectively. Appendix C contains pedestrian accident information presented at the workshop by NHTSA. Appendix $\mathrm{D}$ provides a list of the workshop participants. References cited in the report are listed in a bibliography following the appendices. 


\subsection{OVERVIEW OF THE PEDESTRIAN, BICYCLE, AND PUPIL TRANSPORTATION PROGRAM}

To provide a framework on the proposed projects for later comments by the two working groups, a general workshop session was held to review NHTSA's past and current efforts within the Pedestrian, Bicycle, and Pupil Transportation Program Area. Representatives of the $R \& D$ Office of Driver and Pedestrian Research (Alfred Farina) and the TSP Office of Driver and Pedestrian Programs (Lawrence Pavlinski) addressed the workshop participants. They briefly described the methods their respective offices have used in conducting the pedestrian, bicycle, and pupil transportation research program and recounted their activities in these areas to the present time. This chapter synthesizes the general session discussion. The objectives of the proposed 403 Pedestrian, Bicycle, and Pupil Transportation Research Program are first described. An overview of past and current $R \& D$ and TSP activity follows. The complete text of the $R \& D$ address by Alfred Farina is contained in Appendix A; the complete text of the TSP address by Lawrence Pavlinski is contained in Appendix B.

2.1 Objectives and Priority of the Proposed 403 Pedestrian, Bicycle, and Pupil Transportation Program

The Pedestrian, Bicycle, and Pupil Transportation Program represents one of nine program areas within NHTSA, ranked fourth based on a set of six criteria: accident impact; effectiveness; implementation costs; probability of implementation; increased efficiency of current state safety systems; and implementation time. The program area's rationale is described in the following paragraph:

This constitutes a complex problem-large in the aggregate but small in terms of the particular accident type which can be affected by any one potential solution. However, much is now known about the causes of pedestrian, bicyclist and school bus 
accidents and potential ways of preventing their occurrence. The effectiveness of various measures has been demonstrated particularly for certain pedestrian accident types (ice-creamtruck related, bus-stop related, and "dart-out" accidents). But tests are still underway for regulations and safety messages against such pedestrian accident types as "multiple threat," "vehicle turn/merge," and "intersection dash" accidents. In addition, further research is required for rural pedestrian accidents. Generally, the cost of pedestrian, bicyclist and school bus programs is modest, as they tend to involve ordinances and training expenditures by non-safety agencies such as public schools. Probability of implementation is good, though certain State and local ordinances may encounter considerable opposition because of the inconvenience to normal vehicle parking. (U.S. Department of Transportation 1979, p.17)

NHTSA further describes the nature of the problem and the objectives of its research program in its document entitled "Proposed Plan for Highway Safety Research, Development and Demonstration (Section 403 of title 23, USC) Fiscal Year 1980-1984" (U.S. Department of Transportation 1979):

Excluding motor vehicle occupants, pedestrians constitute the single largest category of fatalities with the number of fatalities averaging just below 8,000 per year over the past four years. NHTSA activities have concentrated on the identification of both urban and rural pedestrian accident types. Because 66 percent of pedestrian fatalities occur in an urban environment, subsequent countermeasure development and demonstration has been concentrated in the urban pedestrian area. NHTSA's urban pedestrian countermeasures development and demonstration program is centered around seven (7) major accident types which account for 57 percent of pedestrian accidents; specifically, dart-out, intersection dash, vehicle turn/merge, multiple threat, bus stop related, ice cream vendor related, and backing-up. In examining rural pedestrian accidents, it has been determined that similar urban threats exist for the rural pedestrian and that a unique set of rural accident types also exist. These include walking along or on the roadway, disabled vehicle related, hitchhiking, mail box, and emergency/police vehicle related.

Bicycle/motor vehicle fatalities have numbered approximately 1,000 per year for the last 4 years, accounting for 2 percent of all motor vehicle fatalities. NHTSA has identified seven (7) frequently occurring accident types which account for about 50 percent of these accidents. These include bicyclist ride-out from a residential driveway or alley, bicyclist riding-out in an intersection controlled 
by a stop sign, motorist entering a roadway from a sign-controlled road and colliding with a bicyclist on an uncontrolled leg of an intersection, motorist overtaking an undetected bicyclist, bicyclist making an unexpected left turn into the path of a motor vehicle approaching from the opposite direction, bicyclist making an unexpected turn/swerve in same direction as motorist, and motorist entering a roadway from a commercial driveway.

Each day some 23 million students are transported to and from schools (in) 380,000 school buses requiring the services of over 400,000 drivers. Although the number of fatalities is low (100 per year or .22 percent of all motor vehicle fatalities), it is estimated that there are over 58,000 school bus accidents annually, the majority of which are directly attributable to school bus driver error. Of the school bus fatalities, one-third are caused directly by the school bus driver backing or driving over pupils entering or leaving the school bus. Research indicates that there is a large turnover in school bus drivers annually. Adequate school bus driver training programs and uniform school bus stop laws are lacking in the states and local communities. (pp.71-72)

\subsection{Overview of $R \& D$ Activity}

The general objective of the $R \& D$ Pedestrian, Bicycle, and Pupil Transportation program is to identify safety problems, and to develop and test countermeasures against these problems. Within this area, NHTSA does not have exclusive jurisdiction. NHTSA shares responsibility in the pedestrian, bicycle, and pupil transportation areas with the Federal Highway Administration (FHWA) and with the Consumer Product Safety Commission (CPSC) in the case of the bicycle's safety. Where appropriate, NHTSA has joined forces with these agencies to accomplish mutual goals.

This section summarizes $R \& D$ efforts in the three topic areas. It is divided into the subsections: pedestrian safety, bicycle safety, and pupil transportation safety. The pedestrian area is presented first.

2.2.1 Pedestrian Safety. The traditional NHTSA research approach has been used by $R \& D$ in the pedestrian safety area. This approach consists of problem identification followed by development of specific countermeasures aimed at the identified problems. Limited tests of the feasibility of the countermeasures are then conducted. If countermeasures 
appear feasible, full-scale field tests and evaluations are implemented. Past pedestrian research efforts, as described in the Workshop General Session, are summarized below.

Problem identification began in 1969 with an urban pedestrian study conducted by the Operations Research Institute. The study focused only on urban pedestrian accidents, since existing statistics had indicated that eighty-five percent of the pedestrian accidents were urban. Furthermore, . sixty-six percent of the pedestrian fatalities were also urban. This study went beyond the traditional demographic approach by classifying pedestrian accidents in terms of the behavioral errors (e.g., faulty search behavior or detection behavior) on the part of the pedestrian or the driver. Environmental and vehicle factors were also analyzed. Using this information, pedestrian accidents were analyzed and sorted into "accident types." An example of an accident type is the "dart out" where children run out on to the street without looking for traffic. Thirty-one accident types were identified. Of these, seven types were found to account for fifty-seven percent of the urban accidents. The same method was used to identify rural pedestrian accident types. While many of the rural accident types appeared to be similar to the urban types, some were found to be more typical of rural roads. These include hitchhiking, walking along a roadway, and accidents related to a disabled vehicle.

The value of identifying specific accident types was to develop knowledge about a particular behavior so that a specific countermeasure aimed at that behavior could be developed. This constituted the second step in NHTSA's research approach. Three primary types of countermeasures were developed: training programs (e.g., anti-dart-out training programs); model traffic regulations (e.g., model ice cream vendor ordinance); and public information safety messages.

Once countermeasures were identified, the next step in the research approach was to test the feasibility of implementing particular countermeasures and their effectiveness in affecting the behavior of concern. For example, countermeasures can be used to break up a behavior sequence and eliminate a behavioral error. An example of this 
countermeasure approach is a training program in proper search behavior before crossing the street for children. A countermeasure may also nullify the effects of a behavioral error. This is the case for the model ice cream vendor ordinance which requires drivers to stop around ice cream vendors; the child may still dart out (behavioral error), but the effects are nullified by the driver's new behavior. A third countermeasure approach may change the situation so that the behavior is not required. Bus loading zone experience is an example of this: changing the location for the loading and unloading of passengers from the near side of the intersection to the far side reduced the need for pedestrians to cross in front of the bus.

If a countermeasure shows indications of affecting the intended behavior, a field test is conducted. A field test is designed to be a larger scale and longer effort than the feasibility effort. Its ultimate goal is to test "bottom line effectiveness"-that is, the effect of the countermeasure on reducing pedestrian accidents.

An illustration of the progress of the $R \& D$ research approach in the pedestrian safety area is contained in the flowchart of projects in Figure 2-1. The projects contained in solid boxes are past or current projects; boxes with broken lines represent proposed projects. As indicated by the flowchart, most of the $R \& D$ projects are linked to previous projects. For example, after the Urban Pedestrian Problem Identification study was completed in FY7l, the development of urban pedestrian countermeasures began in FY72. Several countermeasures were then tested for feasibility (e.g., anti-dart-out training programs, urban pedestrian safety messages) and field tests conducted after feasibility had been established. Table 2-1 presents a list of completed $R \& D$ projects. This list corresponds to the project numbers given in Figure 2-1. The table also contains references for those projects yielding reports.

Presently, $R \& D$ has completed much of its effort in pedestrian problem identification and is planning on deemphasizing that step. Countermeasures that have been field tested and evaluated are now beginning to emerge. For example, pedestrian safety messages aimed at the dart-out behavior 


\section{COMPLETED PROJECTS* \\ PEDESTRIAN/BICYCLIST/PUPIL TRANSPORTATION GROUP OFFICE OF DRIVER AND PEDESTRIAN RESEARCH}

1. Pedestrian Safety: The Identification of Precipitating Factors and Possible Countermeasures, 1/71, PB 197749 (Vol. I), PB 197750 (Vol. II).

2. Urban Pedestrian Accident Countermeasures Experimental Evaluation, 2/75, PB 240255 (Vol. I), PB 240256 (Vol. II), PB 240257 (Vol. II Appendix).

3. Threat Detection Training Programs for Child Pedestrian Safety, 3/75, PB 241181 (Vol. I), PB 241182 (Vol. II).

4. Identification and Test of Pedestrian Safety Messages for Public Education Programs, 3/75, PB 242010.

5. Development of Model Regulations for Pedestrian Safety, 11/77, PB 238280.

6. Causative Factors and Countermeasures for Rural and Suburban Pedestrian Accidents: Accident Data Collection and Analysis, 3/77, PB 265162.

10. A Comparison of Alcohol Involvement in Pedestrians and Pedestrian Casualties, 10/79, PB 80-166275.

11. Identification of Bicyclist/Motor Vehicle Problem Types and Potential Countermeasures, 9/77, PB 282280 (Vol. I), PB 282281 (Vol. II), PB 282572 (Vol. III).

12. Experimental Field Test of the Model Ice Cream Truck Ordinance in Detroit, 4/78, PB 283419.

17. An Audible Automobile Back-Up Pedestrian Warning DeviceDevelopment and Evaluation, 11/76, PB 262806.

18. Enforcement Frequency Sanctions and Compliance Levels for Pedestrian Safety, 4/78, PB 288792.

19. Urban Crossing Problems, 12/78, PB 80-113764.

20. Measurement of Pedestrian Behavior, 0/76, PB 278925.

24. Development of Model Regulations for Rural Pedestrian Safety, 8/80, Currently in print.

* (Note: Numbers correspond to Flow Chart numbers; PB numbers are to be used when ordering copies of the Final Reports from the National Technical Information Service, Springfield, Virginia, 22161.) 
have been fully tested. Similarly, training programs have been tested in Toledo and New Orleans. Model traffic regulations have also been tested and are ready for local implementation.

\subsubsection{Bicycle Safety}

The same research approach used in pedestrian safety has been used in the bicycle safety area. By referring to the flowchart in Figure 2-1, the reader can see the progress of the bicycle safety projects. Problem identification began in 1974 with the Bicyclist/Motor-Vehicle Problem Types and Potential Countermeasures project. The study was patterned after the earlier pedestrian study and generated thirty-six bicycle/motor vehicle accident types.

The next step in the bicycle area was the development of bicycle/motor vehicle countermeasures. An ongoing study has produced approximately ten safety messages addressing a variety of bicycle accident types, nine traffic safety regulations, and four training programs. Future research will test some of these countermeasures.

\subsubsection{Pupil Transportation Safety}

The pupil transportation safety area per se is new to $R \& D$. Because most pupil transportation fatalities are pedestrian accidents, NHTSA was already conducting research in this area through its pedestrian research program. It has recently been added as a separate research area. Presently, $R \& D$ is studying school-bus-related pedestrian accident types and is developing training programs and regulations in this area. $R \& D$ is currently trying to enlarge its accident base in the pupil transportation area. Presently, in-depth accident investigations of forty-six school-busrelated accidents have been developed. Since the accident base is small at the present time, it is not possible to identify all possible school bus accident types and related countermeasures. 


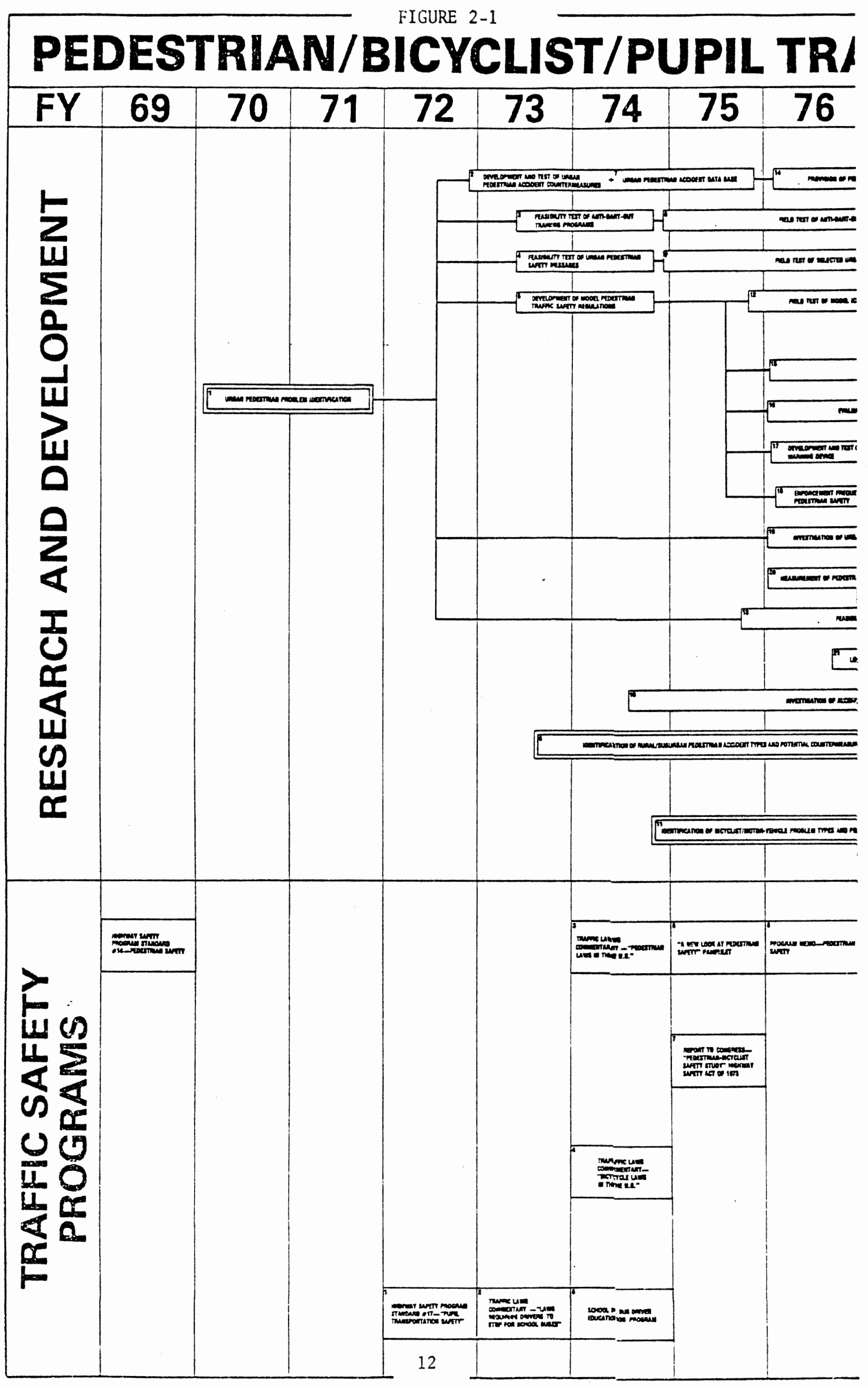


FIGURE 2-1 (Cont'd)

INSPORTATION SAFETY PROGRAM

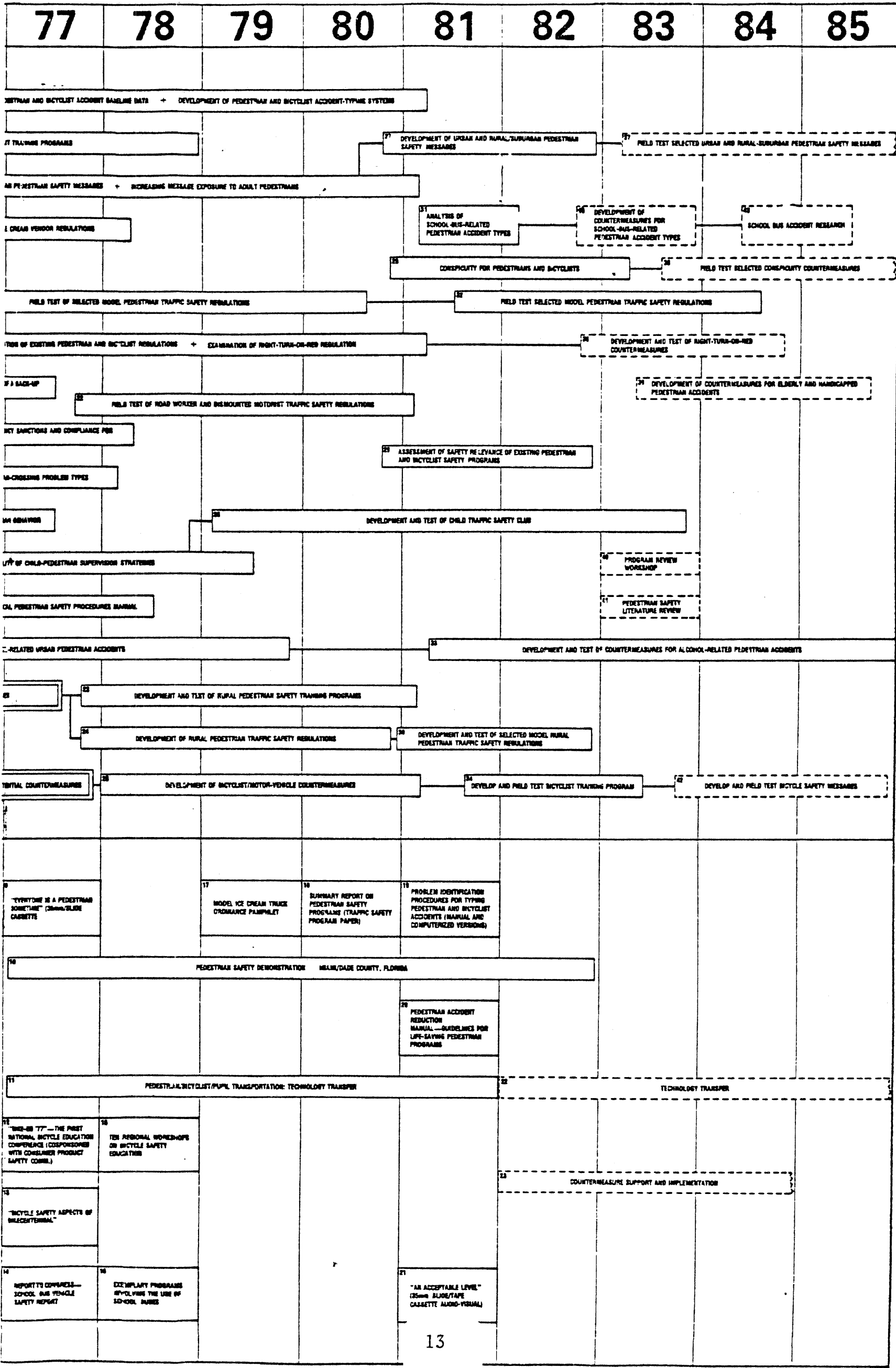




\subsection{Overview of TSP Activity}

Four general objectives of TSP activity in the pedestrian, bicycle, and pupil transportation safety area were identified. First, TSP works with state and local communities to get research products to the local level. This is done by distribution of written and audio-visual materials as well as consultation to state and local agencies. Second, TSP works to establish the authority for the administration of pedestrian, bicycle, and pupil transportation safety programs within a single agency in communities throughout the country. Third, TSP seeks to improve the uniformity of state laws in these three areas by disseminating current information on state laws. Finally, TSP works to instruct local and state users on how to apply the accident types developed by $R \& D$ or how to use such resources as the Pedestrian Accident Reduction Guide (PAR Guide).

This section summarizes the efforts of TSP in the three areas. It is divided into three subsections: pedestrian safety, bicycle safety, and pupil transportation safety. The pedestrian area is presented first.

\subsubsection{Pedestrian Safety}

TSP activity in the pedestrian safety area began in 1969 with the development of Highway Safety Program Standard 14 - Pedestrian Safety. This standard, one of a number of highway safety standards set forth by the U.S. Department of Transportation, provided the impetus for the development of a pedestrian transportation safety program. The Highway Safety Act of 1973 further mandated that the Secretary of Transportation report to Congress on the status of pedestrian and highway safety in the United States. In the course of the development of that report, NHTSA subcontracted with the National Committee on Uniform Traffic Laws and Ordinances to produce a Traffic Laws Commentary on pedestrian laws in the United States. The Report to Congress concluded that there is no need for national legislation on pedestrian safety, rather it is an appropriate activity for the state and local governments.

The efforts of TSP to get pedestrian research products to the state and local users began in 1975 with a pamphlet entitled, "A New Look at 
Pedestrian Safety." This pamphlet was distributed to the NHTSA regional offices and state Governor's Highway Safety Representatives. In 1976, a related document, Pedestrian Safety Program Memorandum, was distributed in the same manner.

Other pamphlets containing results of pedestrian research projects were later produced and distributed. One such pamphlet was the Model Ice Cream Truck Ordinance pamphlet. This pamphlet described the results of a field test in Detroit, Michigan, and advocated the use of the ordinance elsewhere. In 1977, TSP produced and distributed a seventeen minute film, "Everyone is a Pedestrian Sometime," to spur interest in pedestrian safety at the local and state level.

The most recent effort by TSP in pedestrian safety has been the development of the Pedestrian Accident Reduction Guide (PAR Guide). This manual takes the materials developed and tested by $R \& D$ and presents them in a package that can be used by city and state agencies. It shows users how to classify pedestrian accidents by type and illustrates the countermeasures that are most effective for particular accident types.

TSP is also currently sponsoring a pedestrian safety demonstration project in Dade County, Florida. It continues to distribute pedestrian safety research results and products through its ongoing technology transfer function.

\subsubsection{Bicycle Safety}

Unlike the pedestrian safety area, there is no NHTSA national standard on bicycle safety. Such a standard has been considered in the past, but none has been developed. The only bicycle safety standard that currently exists is a Consumer Product Safety Commission Standard. That standard applies to the bicycle itself and does not address other variables (e.g., bicyclist behavior) involved in bicycle safety.

The beginning of bicycle safety programs in TSP parallels that of the pedestrian safety area. In the course of the development of the Pedestrian Bicyclist Report to Congress, a Traffic Laws Commentary on Bicycle Laws in the United States was prepared by the National 
Commission on Uniform Traffic Laws and Ordinances. Two years later, in 1977, TSP cosponsored "Bike-ED 77"-the first National Bicycle Education Conference--with the Consumer Product Safety Commission. From that conference, TSP identified the need to disseminate information on bicycle safety education to the state and local level. In 1977, ten regional workshops on bicycle safety education were convened to meet this need. TSP also participated with the Federal Highway Administration in a oneweek workshop on urban considerations related to pedestrians and bicyclists at the request of individual states. NHTSA continues to distribute bicycle safety research results and products through its ongoing technology-transfer process within TSP.

In addition to TSP's activity in technology transfer, bicycle safety research products are being distributed by other organizations using NHTSA-sponsored research: 1) Travellers Insurance has produced a film, "It's Your Move," currently being loaned throughout the country; 2) the American Automobile Association (AAA) Foundation has produced a booklet for distribution entitled, "Bicycle Safety Facts and Issues"; and 3) Fiesta Films has produced two new bicycle safety films.

\subsubsection{Pupil Transportation Safety}

The pupil transportation safety area has paralleled the development of the pedestrian and bicycle safety areas. TSP activity began with the development of NHTSA Highway Safety Program Standard 17 - Pupil Transportation Safety - in 1972. While that was being developed, TSP subcontracted with the National Committee on Uniform Traffic Laws and Ordinances to prepare a Traffic Laws Commentary on "Laws Requiring Drivers to Stop for School Buses." This was completed in 1973. In 1974, following this activity, TSP developed a school bus driver training program for distribution at the state and local level. In 1977, TSP submitted its School Bus Vehicle Safety Report to Congress. Literature describing exemplary school bus programs has also been produced and distributed.

TSP has developed and distributed a seventeen-minute film on school bus safety entitled, "An Acceptable Level." Research results and products 
continue to be distributed through TSP's ongoing technology transfer function.

\subsection{Summary}

The Pedestrian, Bicycle, and Pupil Transportation program is one of nine 403 program areas within NHTSA, ranked fourth in priority for future efforts. Activity within these areas is divided between two NHTSA offices: research and development activity is performed by Research and Development (R\&D); the distribution of research results and products is performed by the Office of Traffic Safety Programs (TSP).

The approach used by $R \& D$ is the same for the pedestrian, bicycle, and pupil transportation safety areas. Initial research projects are undertaken to identify the safety problems. This is accomplished by analyzing accidents in the three topic areas and identifying accident types. Specific countermeasures are then developed to address the accident types. Countermeasures within these three areas have for the most part been either training programs, model traffic safety regulations, or public information messages. After countermeasures have been developed, feasibility testing is conducted to determine if the proposed countermeasures can be effectively implemented. If a countermeasure is seen to be feasible, a full-scale field test is conducted to determine whether the countermeasure is effective in reducing accidents.

In this $R \& D$ program, the pedestrian area is the most heavily funded and most advanced area. Problem identification and countermeasure development have essentially been conducted. Current emphasis is on the feasibility and field testing of countermeasures. In the bicycle and pupil transportation areas, problem identification remains an important activity.

In TSP, all three program areas also parallel each other. Each began with the preparation of a summary of laws regulating the area as well as a Report to Congress. With the exception of the bicycle area, NHTSA highway safety standards were also developed. Training programs and workshops for state and local users have been conducted in all three areas. Literature and films have been sent to NHTSA regional offices and the 
Governors' Highway Safety Representatives for distribution at the state and local level. A manual has also been developed to provide instruction on classifying pedestrian and bicycle accidents and selecting appropriate countermeasures for state and local users. 


\subsection{RESEARCH AND DEVELOPMENT}

The first working session dealt with proposed research and development (R\&D) projects within the pedestrian, bicycle, and pupil transportation program area. Nine such projects were identified by NHTSA.

\subsection{Background}

The proposed research and development activity presented by NHTSA at the workshop begins with fiscal year (FY) 1982 and extends through 1985. Efforts are distributed across the three areas of pedestrian, bicycle, and pupil transportation safety. Two studies focus solely on pupil transportation; one on bicycle safety, and two on pedestrian safety. Two projects deal with both bicycle and pedestrian safety. The remaining two are concerned with all three safety areas.

The primary focus of the proposed reseach and development activity is countermeasure identification, development, and evaluation. Seven projects address this activity. One project is focused upon problem identification. The ninth project provides for a mechanism of external review of proposed 403 projects.

\subsection{Discussion}

The nine $R \& D$ projects were reviewed by participants in the first working session. Participants addressed the relevancy and necessity of each project to the overall program objectives. The sufficiency of the project in achieving safety goals was also considered. Comments made by participants were usually specific to each project discussed. However, participants did make a number of comments that generalized to all $R \& D$ activity in the program area. This section presents both general and project-specific comments made by the workshop participants. 


\subsubsection{General Comments}

For the most part, participants supported the relevancy and necessity of the proposed $R \& D$ projects. Many panel members reported some difficulty in adequately assessing the objectives and methods of the projects under discussion. This difficulty stemmed from the fact that, in most cases, the projects under discussion were contingent upon ongoing projects whose results were not yet determined. These participants stated that a clear understanding of the research upon which the proposed projects are based is necessary to intelligently discuss their need or value. NHTSA resource persons recognized that this problem existed and assured participants that the proposed projects would be undertaken only if current efforts indicated a need for such research. It was suggested that, at the workshop, participants limit themselves to a consideration of whether projects followed in a logical sequence, assuming that current efforts produced results warranting further research.

Critical comments, generally, were directed at the sufficiency of the projects' methods for accomplishing the stated objectives. Much of this concern centered around funding levels. These levels were viewed as lower than what is necessary to do a "first class job." One participant commented that at current funding levels "NHTSA was buying a lot of Chevrolets, when for more difficult projects, they should be buying Cadillacs." Most participants agreed that money was tighter than it should be, both in terms of dollars per project and total program dollars.

Related to the above comments, several participants suggested that NHTSA establish a mechanism for getting out of a proposed research chain. Such a mechanism could be used if a current project is not "panning out" or, conversely, does better than expected and eliminates the need for further research. One participant suggested the establishment of a "wish list" of unfunded priority projects that could be funded if money became available in this manner. NHTSA personnel indicated that they were trying to improve their procedures in this area. One potential problem was noted; i.e., the existence of different perceptions as to whether further research in an area is warranted. It is likely that 
disagreement will always exist in the discretionary process of deciding how long to fund a particular research area.

Greater communication among government agencies was strongly recommended by participants. An emphasis upon treating the problem as a whole was expressed. For example, it was noted that NHTSA deals only with bicycle-motor vehicle accidents; other agencies are dealing with such accidents as bicycle-bicycle collisions or falling off bicycles. As one participant stated, NHTSA may be "suboptimizing" by treating only one aspect of the problem. The group strongly endorsed the concept of interagency exchange of information. Not only would more complete information be made available by such exchange, but duplication of efforts would be less likely to occur. Participants recognized that such activity should not be one-sided on NHTSA's part but needed the cooperation of other agencies as well.

Problems associated with the regulations of the Office of Management and Budget (OMB) regarding federally sponsored surveys were raised in both working groups. It was agreed that the OMB restrictions on questionnaires severely limited the quality of research. It was noted that most of the proposed studies needed some measurement component for adequate evaluation. One participant mentioned that these restrictions especially affect the area of bicycle safety, where there is little information about bicyclists and no way of obtaining it short of a survey. NHTSA resource persons agreed that $O M B$ requirements placed unnecessary restrictions on highway safety research. They noted that NHTSA is limited by OMB to a specific number of surveys per year. In order to conduct new surveys, an old one must first be eliminated. Thus, many projects which could use surveys as a research method must use other methods to obtain information. One NHTSA resource person suggested that individuals contact their state representatives to let them know about the problem. Another suggestion was to find a way to initiate a General Accounting Office (GAO) inquiry to determine if the federal government is operating in the most efficient manner by placing restrictions on data collection. Finally, one participant noted the irony of having one government agency 
putting requirements in their procurements to have the contractor devise techniques to circumvent another agency's regulations.

\subsubsection{Project-Specific Comments}

Project descriptions were provided to participants by NHTSA at the workshop. The NHTSA project description is presented in each subsection below; group comments follow. The project numbers refer to numbers on the project flowchart in Figure 2-1 (see Chapter Two).

\subsubsection{Transportation of the Handicapped (Project \#35)}

The primary thrust of this study is problem identification. The NHTSA project description is as follows:

Transportation of the Handicapped $(60 \mathrm{~K})$

$$
\text { FY } 182-60 \mathrm{~K}
$$

\section{Summary/Overview}

Approximately 8 million children are now eligible for transportation via the Education of all Handicapped Children Act (P.L. 94 - 142). This project will analyze available school-bus accident data to determine if a safety problem exists for this group and, if so, to develop countermeasure recommendations. Information (report) from this study will be made available to TSP for review.

\section{$\underline{\text { Purpose/Justification }}$}

Many handicapped children are now eligible for school bus transportation under a recently passed law.

\section{Objective}

The objective of this study is to determine if a safety problem exists for handicapped children transported by school buses, and, if so, to develop countermeasure recommendations which have the potential for reducing such accidents.

\section{Method}

- Select a candidate State(s) whose data tapes/hard copy reports of school bus accidents are suitable for analysis.

- Plan for accessing/analyzing the data from tapes and hard copy. 
- Prepare a report for internal review which provides findings and make countermeasure recommendations. A panel will discuss candidate approaches (driver training) to be taken with drivers of school buses, child passengers, and significant others.

\section{$\underline{\text { Results }}$}

This project will provide information regarding the nature and magnitude of the handicapped child school bus problem and countermeasure recommendations having promise for reducing them.

\section{Application}

Information on the extent of the problem and countermeasure recommendations will be made available for technology transfer.

The workshop panel generally supported a problem identification effort in this area. Participants agreed that a necessary first step in this project was to determine if a safety problem exists for handicapped children transported by school busses. One participant noted that there seems to be an assumption by NHTSA that a problem exists, while some state records do not support this notion. Another participant viewed the study as worthwhile only if the question of whether a problem exists could be answered within the proposed funding level. This participant also did not believe the problem was large enough to warrant the expenditure of additional resources.

Several methods for determining whether a problem exists were suggested. One participant suggested that a literature review be conducted to determine if any previous studies have identified safety problems associated with transporting handicapped children. Other participants suggested that a census of the fifty states be conducted to determine the number of states identifying this area as a safety problem. It was the consensus of participants that some sort of general problem identification step was necessary before selecting a state for data analysis. The census approach was the most strongly recommended method for identifying the states with this problem and for gathering the data to support further analysis of the problem. Participants also recommended that some flexibility be included in the general problem identification step to pursue 
a different problem if one is identified.

A related question raised by workshop participants was the criteria used by NHTSA in deciding to pursue countermeasures for a particular problem area. NHTSA personnel responded that the size of the problem is an important consideration in the allocation of funds among the program area projects. One participant suggested that while the size of the problem may be important, it should not be conclusive: a maximally effective countermeasure aimed at a small problem may be more worthwhile than a minimally effective countermeasure aimed at a big problem. NHTSA personnel agreed that there was a need to balance considerations other than the size of the problem.

While the problem identification effort of this study was generally viewed as relevant and necessary, the sufficiency of the project to accomplish its stated objectives was questioned. A basic issue raised by the panel was the availability of the data NHTSA proposed to use for its analyses of accidents involving handicapped children. While participants agreed that existing data files might provide useful information, they did not believe such files would be very productive. One participant observed that accident reports rarely if ever noted whether victims were mentally or physically disabled. Other participants strongly supported this observation. Several alternative methods of obtaining the information were identified. Some participants suggested a multi-disciplinary accident investigation (MDAI) approach in which a small set of school bus accidents are identified and studied in depth. Others noted that this method would probably not be feasible because of the relative infrequency of these type of accidents. It was suggested that data sources other than police accident reports be identified and used to determine the extent to which school bus accidents involve handicapped children. Records kept by special education schools and the state agencies responsible for the transportation of special education students were two suggested sources. It was the consensus of the group that these data may be available from various sources if the project was limited to children transported in special equipment, but that it would be more difficult to get for handicapped 
children transported by other means. Other possible data sources identified by the panel included: school bus operator reports, school district reports, and rehabilitation center files.

The workshop panel further identified several issues in need of delimitation before any data collection strategies were undertaken. These include:

- definition of the handicapped population to be studied;

- identification of the age range of the population to be studied;

- identification of the modes of handicapped transportation to be included in the study;

- definition of accident for the purpose of the study; and

- identification of the safety issues to be addressed by the study.

Panel members noted that handicaps take a variety of forms. These may include mental, emotional, as well as physical handicaps. Participants wanted to know how NHTSA defined handicapped children in terms of the project. NHTSA personnel responded that it was their interpretation that only children needing special equipment to be transported were included. In response, several participants noted that NHTSA's estimate of eight million children was probably exaggerated; many of the eight million children eligible for handicapped transportation are learning disabled and do not need special equipment. It was recommended that NHTSA carefully delineate the population to be addressed in the study. One participant did question whether handicapped individuals can be adequately identified given the constraints of the Federal Privacy Act of 1974 and other related privacy legislation. While many physical disabilities can be detected readily, more subtle forms of handicaps may be difficult to identify.

The age range of the population to be studied was also a concern for some panel members. Participants questioned whether the study would be limited to persons under the age of twenty-one. It was pointed out that many school districts continue to transport handicapped individuals throughout adulthood. This includes transportation to programs outside the 
regular district jurisdiction, such as to special education programs, rehabilitation centers, and private sector programs supported by public funds. Participants suggested NHTSA carefully specify such items for this project.

A number of participants wondered whether the use of the phrase "school bus" was a deliberate limitation in the project description. It was noted that in some school districts the handicapped transportation system makes use of buses not designated as school buses per se as well as vehicles not even resembling a school bus. Furthermore, the distinction between handicapped students needing special equipment and those not needing it became blurred. NHTSA resource persons acknowledged that the project will have to address handicapped children transported on buses not requiring special equipment. Panel members suggested that NHTSA take such alternate transportation modes into account in defining data collection efforts.

Participants also asked NHTSA to clarify the type of accident to be studied; that is, is the focus on pedestrian accidents or on accidents that occur while the vehicle is in transit. The school bus accident problem has traditionally been defined as the case of the child being hit by a vehicle while going to or from the school bus. Participants noted that many of the handicapped now being transported are so severely disabled that they are not able to walk. This led one participant to suggest that if the scope of the study is limited to those accidents occurring while going to or from the bus, then the study is not worth doing.

Finally, participants recommended that NHTSA clarify the safety issues to be addressed by the project. Such issues include the incidence of such accidents, the population at risk, and the nature of the problem. NHTSA should clearly state the specific issues to be addressed in the study.

\subsubsection{Development and Test of Right-Turn-On-Red (RTOR)} Countermeasures (Project \#36)

NHTSA currently has a project investigating the accident problems of right-turn-on-red (see Block 16 in Figure 2-1). The implementation of the 
proposed study is dependent upon the results of that ongoing study. The proposed study will identify countermeasures for the right-turn-on-red accident. Its project description follows.

Development and Test of Right-Turn-On-Red (RTOR) Countermeasures (150K)

$$
\text { FY' } 82 \text { - 100K; FY } 183-50 \mathrm{~K}
$$

\section{Summary/Overview}

An ongoing project will determine whether the Western rule RightTurn-On-Red (RTOR) regulation is associated with an increase in pedestrian and/or bicyclist/motor-vehicle accidents, or if it results in unique problem (accident) types. If RTOR is found to be a problem, this project will develop and test countermeasures for improving pedestrian and bicyclist safety while retaining the energy-conserving features of the RTOR regulation. Information about promising countermeasures will be made available for technology transfer.

\section{Purpose/Justification}

In an ongoing study, existing accident data are being analyzed to determine the incidence of right-turning accidents at signalized intersections. Hard copy accident reports for RTOR accidents will also be analyzed. If these data indicate that a RTOR problem exists, a countermeasure development study will be conducted in FY'82.

\section{Objectives}

The objective of this $24-$ month project is to develop and test countermeasures for reducing RTOR accidents while retaining the energy-conserving features of the RTOR regulations.

\section{Method}

- Review the results of NHTSA and other available data (e.g., Insurance Institute for Highway Safety Report) for RTOR accidents and review suggested solutions.

- Develop recommended solutions (e.g., conspicuity-enhancing countermeasures for pedestrians/bicyclists; safety messages).

- Develop a plan to test government-selected countermeasures. This plan will include information and procedures on the design of the study, and the data-analysis technique(s) to be employed.

- Develop countermeasures for reducing RTOR accidents (e.g., 
pedestrian/motorist safety messages).

- Conduct a small-scale field test of the countermeasures using, as a minimum, knowledge gain and/or behavior-change measures to determine countermeasure effectiveness.

\section{$\underline{\text { Results }}$}

Information will be acquired on the effectiveness of one or more tested countermeasures.

\section{Application}

Information on possible solutions to the RTOR problem will be made available for technology transfer.

Many participants expressed concern that they could not adequately address the issue of whether this project should be done because there were currently no results from the ongoing project. NHTSA recognized these concerns and assured participants that the proposed project would be pursued only if the current project showed that a specific right-turn-on-red problem existed. Participants agreed that if the current project warrants further research, the proposed project would be relevant. One participant questioned whether the current project is considering the problems associated with blind pedestrians and right-turn-on-red. NHTSA responded that such problems are being included in the data analysis but are not a primary focus of the study.

Several issues were raised with respect to the research method for the proposed project. One participant wanted to know if NHTSA had an experimental design in mind. NHTSA responded that it has not been developed but in all likelihood would be a traditional experimental approach involving a control group. A number of participants suggested that these accidents be compared to right-turn-on-green accidents.

Many participants thought that instead of just looking at states that had recently enacted RTOR provisions, the proposed project should compare states that had recently passed it with states that have had it over a length of time (e.g., California). NHTSA was also asked to consider possible differences in accident occurrence and prevention posed by 
children and various minority groups.

Several participants pointed out that the proposed project, as described by NHTSA, is committed to keeping right-turn-on-red and developing countermeasures to increase the safety of its use. These participants recommended that NHTSA also consider the abolishment or selective use of right-turn-on-red in places where it is found to be a safety problem. NHTSA responded that the purpose of the project was to identify possible solutions to increase the safe use of right-turn-on-red; if no such solutions could be developed, NHTSA could certainly advocate abolishment. One issue of concern in this discussion was that of pedestrian and bicyclist mobility. It was noted that the reduced mobility of these groups due to right-turn-on-red is probably affecting the number of accidents. An observation of the dynamics of right-turn-on-red was suggested to assess how mobility is affected. Retaining the mobility of pedestrians and cyclists was seen as important as the energy conservation aspect of rightturn-on-red.

Several participants pointed out that the current schedule of the proposed project should be pushed back, since the project upon which it is predicated is only at a preliminary stage. NHTSA agreed that this may have to be done but indicated there is still the possibility that the current project will produce its findings on time.

\subsubsection{Field Test of Urban and Rural Pedestrian Safety Messages} (Project \#37)

This study is also linked to a number of other NHTSA efforts (see Blocks 4, 9, and 27 in Figure 2-1). The implementation of the proposed project is dependent upon a current effort focusing upon the development of pedestrian safety messages. The project description reads:

Field Test of Urban and Rural Pedestrian Safety Messages (400K) FY 183 - 150K; FY 184 - 150K; FY ${ }^{1} 85$ - 100K

\section{Summary/Overview}

Approximately 8000 pedestrians are killed yearly in collisions with motor vehicles. An ongoing study will develop and pretest PI\&E 
materials for up to five urban/rural/suburban pedestrian accident types (e.g., walking-along-roadway, dart-out, bus-stop related, backup accident, and mail-box related.) Also, media materials suitable for reproduction will be made available. The proposed study will determine, via a field test, the accident-reduction effectiveness of the most promising of these message materials. The output of this three-year study will be PI\&E materials (pamphlets, posters, TV/radio spots, etc.) suitable for mass media use.

\section{Purpose/Justification}

Past NHTSA-sponsored research in several urban areas (e.g., Los Angeles, Milwaukee) suggests that the introduction of public information and education safety messages (via TV/radio spots and in-school films) resulted in an approximately 20 percent decrease in dart and dash type accidents for children.

\section{Objectives}

The objective of this 36 -month project will be to determine the accident-reduction effectiveness of promising PI\&E safety message materials for reducing specific types of urban and rural pedestrian accidents.

\section{Method}

- Selection of safety messages for experimental field test (based on information from previous study).

- Development of field-test plan (includes site selection, experimental design, procedures to be employed, data analysis techniques, etc.).

- Implementation of field test (measures to include accident reduction, behavior change, knowledge gain and process information).

\section{$\underline{\text { Results }}$}

Public Information and Education Safety materials suitable for mass media use.

\section{Application}

The materials found to be effective for reducing specific accident types will be made available for technology transfer.

The panel viewed this project as both relevant and necessary. One participant questioned what the practitioner would be able to get from the 
project. NHTSA resource persons replied that the output would include a description of the circumstances necessary for the effective use of each countermeasure tested. There was some sentiment among participants for more detailed information for practitioners to use in "fine tuning" each countermeasure.

Questions were raised with regard to scope and method. The methods as stated were seen to be quite broad and encompass a variety of techniques. Concerns about what was being tested were raised. Participants noted the project was not clear about whether the message or the method of communication is to be tested. It was recommended that NHTSA deal specifically in the project description with the issues of quality of production and method of delivery.

Several participants sought clarification about the groups to whom the PI\&E messages would be directed (e.g., children, adults, elderly people, etc.). NHTSA informed participants that all age groups would be included in the field test. NHTSA resource persons also indicated that mass media mechanisms other than radio and television would be included in the field tests.

One participant asked whether air time for the messages would be purchased. NHTSA resource persons noted that NHTSA is precluded from engaging in paid safety advertising; rather, it is dependent upon public service announcements.

A final issue raised by participants dealt with evaluation measures. Several participants expressed concern that NHTSA's plans to observe actual behavior changes would be difficult, particularly in rural areas, because of the obtrusiveness of observers.

Panel members generally felt the funding level for this project was reasonable.

\subsubsection{Field Test of Selected Conspicuity Countermeasures for} Pedestrians and Bicyclists (Project \#38)

The project is described as follows. 
Field Test of Selected Conspicuity Countermeasures for Pedestrians and Bicyclists (300K)

FY '83 - 150K; FY ' 84 - 150K

\section{Summary/Overview}

A prior NHTSA research effort determined the nature and magnitude of the conspicuity problem involving pedestrians and bicyclists, and tested, in a controlled field setting, selected daytime and nighttime conspicuity-enhancing countermeasures. This study will field test the most promising of these countermeasure devices and materials for their effectiveness in obtaining positive behavior change and/or accident reduction. Results will include information on effective daytime and nighttime conspicuity-enhancing countermeasures and implementation procedures.

\section{Purpose/Justification}

A previous NHTSA research project will have tested, in a controlled field setting, promising daytime and nighttime conspicuity-enhancing countermeasures and procedures. If the previous study identifies useful countermeasures, then they will be tested on this project in an operational setting.

\section{Objectives}

The objective of this research study will be to field test selected pedestrian and bicyclist daytime and nighttime conspicuity countermeasures for their effectiveness in obtaining positive behavioral change and/or accident reduction.

\section{Method}

- Review the results from the previous project and select potentially effective countermeasures for use in field-testing.

- Develop a field-test plan. This plan will include site selection criteria, the experimental design, means of obtaining cooperation at a site, assessment measures, data-analysis techniques, etc.

- Develop a PI\&E support package for mounting a campaign aimed at familiarizing target groups with various conspicuity-enhancing materials and devices.

- Implement the field test at specific sites. An evaluation will be made of process information, knowledge gain and behavior change (e.g., nighttime use of retroreflective materials and devices for pedestrians and bicyclists). Also, an attempt will be made to obtain accident-reduction information if possible (e.g., \% nighttime pedestrian accident reduction). 
- Develop conspicuity performance-based recommendations and support materials.

$\underline{\text { Results }}$

Information will be obtained on effective daytime/nighttime conspicuity-enhancing countermeasures and implementation procedures for pedestrians and bicyclists. Also, a materials package (recommended performance-based guidelines, PI\&E materials) will be developed for use by State/local personnel in conspicuity-related accidents.

\section{Application}

The materials package will be made available for technology transfer.

The proposed project is linked to an ongoing study at NHTSA (see Block 28 in Figure 2-1). It is intended to close the loop on NHTSA's conspicuity efforts. Efforts will be directed toward the usability and acceptability of conspicuity countermeasures.

The workshop participants generally agreed that a project like this was worthwhile. However, objections were raised regarding the lack of emphasis placed on obtaining accident reduction data related to countermeasure use. Several participants pointed out that the collection of accident reduction data seemed to be an afterthought in the project description. Group members recommended that such data should be an ultimate goal of the project. It was the consensus of Group B that NHTSA should not waste money on showing that people can be induced to wear or use conspicuity-enhancing devices if there are no data to show that the devices are effective in reducing accidents. The group recognized that proxy measures such as acceptability were important considerations, but made clear that the ultimate goal should be accident reduction.

Several concerns with the project's proposed method were raised. First, several participants indicated that the body of literature on conspicuity in motorcycle research should be reviewed for relevancy in the project. NHTSA resource persons agreed that such an effort was appropriate but noted that many conspicuity requirements in the motorcycle area involve 
lighting requirements. The relevancy of lighting solutions to the pedestrian and bicycle area is yet to be determined.

Several participants discussed the possibility of developing standardized markings for bicyclists similar to the markings for slow-moving vehicles. There was some agreement among participants that the development of a standardized bicycle identification symbol to differentiate between other types of road users such as joggers and pedestrians would be useful. One participant questioned this recommendation, noting that research indicates the accident problem is a matter of not seeing what is on the road rather than not knowing what the object is. Other participants countered this argument by expressing the view that a large number of bicycle accidents are caused by drivers not knowing the actions of the object they are passing. It was their opinion that knowing the object is a bicyclist would help in such instances.

Members of the workshop group pointed out that two behavioral issues need to be addressed by the study's method, no matter what the specific conspicuity measure is: instructions for the specific use of the conspicuity measure and more general training information. It is important that pedestrians and cyclists use conspicuity devices properly. However, it was also pointed out that there are times when pedestrians and cyclists probably will not be conspicuous no matter what they do. Participants recommended that these groups be provided with information addressing this latter point along with any specific conspicuity instructions.

An evaluation of the possible negative effects of a conspicuity countermeasure was recommended for inclusion in this project. Possible effects include an increase in risk to the pedestrians and bicyclists who do not make use of the conspicuity devices. Similarly, a number of participants recommended that there be an assessment of the degree to which users of conspicuity devices increase their risky behaviors because of an increased feeling of safety due to the devices.

Finally, participants suggested that NHTSA investigate strategies for speeding up the adoption process if effective conspicuity countermeasures are identified. Panel members recommended efforts be made to get one 
population group (e.g., joggers; competitive cyclists) to use the conspicuity measure. It was suggested that attention might flood over to pedestrian and other bicyclist groups.

\subsubsection{Identification and Test of Countermeasures for}

Elderly/Handicapped Pedestrians (Project \#39)

This project is intended to look at the unique problems of the elderly and the handicapped pedestrian. Its project description reads:

Identification and Test of Countermeasures for Elderly/Handicapped Pedestrians (200K)

$$
\text { FY } 183 \text { - 100K; FY } 184-100 \mathrm{~K}
$$

\section{Summary/Overview}

This project will examine existing accident data to determine whether unique factors contribute to accidents involving elderly and handicapped pedestrians. Existing countermeasures will be reviewed to assess their appropriateness to the special capabilities of the two groups. If warranted, existing countermeasures will be tailored to the needs of these groups. A future field test of one or more of these countermeasures may be considered.

\section{Purpose/Justification}

Up to this time, NHTSA pedestrian safety research has not treated these two groups separately, but has dealt with them as they formed a part of the target groups involved in particular types of accidents. Pedestrians 65 years of age or older have been found to be involved in about 19 percent of the urban pedestrian accidents and 6 percent of the urban rural accidents. Handicapped pedestrians have been reported in approximately 8 percent of the urban and 4 percent of the rural accidents.

\section{Objectives}

This study will examine existing accident data involving older and handicapped pedestrians to determine if there are unique factors contributing to their accident involvement. If such are found, another objective will be to repackage, as necessary, existing countermeasures to the needs of these two groups.

\section{Method}

- Examine existing NHTSA/FHWA accident data to determine whether unique factors (e.g., poor vision, hearing, mobility) 
contribute to elderly/handicapped pedestrian accidents.

- Prepare a document for internal review, indicating problems and causes of accidents for the elderly and handicapped.

- If warranted by the data, review existing pedestrian countermeasures for possible modification.

- Set up focus groups to discuss: (1) the awareness of those groups to the problem; and, (2) their willingness to accept proposed modifications for behavior change.

- Refine the countermeasures as needed.

- Pilot test one or more countermeasures on target audiences, obtaining information about behavior change, and knowledge gain.

$\underline{\text { Results }}$

Revised/repackaged countermeasures which are more specific to the accident needs of elderly and handicapped.

\section{Application}

A future field test of one or more of these countermeasures may be considered.

Panel members generally supported the proposed study. Several participants recommended expanding it to include the elderly bicyclist. A number of reasons supporting this recommendation as well as the proposed project were stated. The increasing life span sinply means that there will be greater numbers of elderly pedestrians and bicyclists. Because of limited incomes, more elderly persons as well as handicapped individuals are making use of the bicycle for transportation. Finally, the increasing strength of the mainstreaming movement means an increasing number of handicapped pedestrians and bicyclists.

Participants had a number of comments about the methods proposed for this project. Several participants objected to NHTSA's view that only accidents involving motor vehicles would be studied. FHWA resource persons agreed that NHTSA was not going to get a good cross-section of accidents if it studied only motor vehicle accidents. NHTSA resource persons recognized this problem but indicated that because of agency 
priorities and funding limitations only those involving motor vehicles could be studied.

Rising out of this discussion, several participants recommended that in future funding, perhaps in the 1985 Five Year Plan, the setting of priorities take into consideration non-motor-vehicle accidents as well as motor vehicle accidents. Other participants, however, cautioned against taking too limited an amount of resources and trying to spread them across too broad an area of research. There was no general consensus among participants with respect to this issue.

Panel members recommended that this project examine all research in this area rather than just NHTSA/FHWA accident data. Group B recommended unanimously that the description of the project method be changed to reflect that opinion. Similarly, the panel recommended that the focus groups mentioned in the project method include drivers. NHTSA personnel agreed.

Finally, several participants noted that the definition of handicapped in this project was vague. One participant wanted to know if visual-motor handicaps were included or only physically handicapped pedestrians. NHTSA replied that if the handicap was related to a motor vehicle accident situation it was relevant. Another participant pointed out that given the present definition, there was a very large study population; at some point, the population needs to be delineated.

Panel members offered little comment on the sufficiency of the proposed method. One participant did express concern that the level of effort might be low, given the range and diversity of target groups included in the study.

\subsubsection{Pedestrian/Bicyclist/Pupil Transportation Program Review Workshop (Project \#40}

The purpose of this project is to ensure that future plans are reviewed by the highway safety community. The project description follows.

Pedestrian/Bicyclist/Pupil Transportation Program Review Workshop $(50 \mathrm{~K})$ 


$$
\text { FY } 183-50 \mathrm{~K}
$$

\section{Summary/Overview}

In FY 79 and FY 181 , reviews were conducted of 403 Program plans in the areas of Pedestrian/Bicyclist/Pupil Transportation. This project provides for another periodic review of the updated plan in FY 183. A workshop will be held involving respresentatives from the government, research community, and State safety personnel. A report for public review will be made available.

\section{Purpose/Justification}

This activity provides for external review of NHTSA's 403 Program plans.

\section{Objectives}

The objective of this project will be to: (1) provide logistical and other support needed to conduct an outside review of NHTSA's 403 Program Plans in the areas of Pedestrian/Bicyclist/Pupil Transportation Safety; and (2) provide a report which documents the results of the outside review, including reviewer comments and recommendations for future planning.

\section{Method}

- Review previous 403 Workshop documents.

- Provide the logistical support needed to conduct a 2-3 day workshop, prior to and during the workshop.

- Write a report documenting the participants' comments about the Pedestrian/Bicyclist/Pupil Transportation 403 plan.

\section{Results}

- A document synthesizing the comments of the workshop participants, including recommended program changes, will be made available for public review. Also, under separate cover a paper shall be prepared which indicates any logistical problems encountered and their proposed solutions.

\section{Application}

- The document describing the results of the workshop shall be utilized in future 403 Program planning.

NHTSA anticipates conducting a workshop in the pedestrian, bicyclist, pupil 
transportation area about every two years.

The panel strongly supported this project as both relevant and necessary. The view was expressed that it is the responsibility of the government to seek information from the best sources it can find; not to do so is irresponsible. It was pointed out that the relatively small amount spent on the workshop review process would probably save money elsewhere, for example, on projects that are simply not viable. Furthermore, it was noted that a recommendation to conduct such a review process was also made at the Transportation Research Board (TRB) Conference that reviewed the NHTSA 403 Program in May 1979.

Specific suggestions regarding workshop strategies were made by participants. First, several participants believed that the wrong group of people were often convened for workshops. One participant described the usual participants as having worked in pedestrian safety research on a national level and as not being sensitive to the needs of communities. It was suggested that state program officers or other practitioners at the state and local level be surveyed to get their input. NHTSA resource persons indicated that there is currently a mechanism for obtaining practitioner input under each state's 402 plan but that it is rarely used; when used, nonspecific statements, such as, "more research in alcohol and highway safety" are frequently found. The group recommended that an instrument should be developed to get practitioners to better focus on specific needs.

NHTSA resource persons also indicated that they did not agree with the proposal to gather together local practitioners rather than researchers, bcause that approach was often "like reinventing the wheel." Several participants pointed out that there were really two basic inputs that NHTSA was requesting. Recommendations on research methods were certainly appropriate to the research community; input about states' and communities' needs was appropriate to both groups. It was suggested that the input did not have to come via a workshop, but many participants agreed that NHTSA should make greater efforts to solicit practitioner input. 
At least one panel member expressed concerns that too many of the workshop participants selected by NHTSA were either current or future NHTSA contractors. It was suggested that such participants have a vested interest in supporting their own projects. A broader representation from the research community in this area was seen as desirable for such a review process.

Participants also indicated that the workshop method is often inadequate to obtain even researcher input. Several participants expressed doubts that NHTSA would change project statements to reflect the input provided by the workshop participants. They noted that many people felt nothing was accomplished by the May 1979 TRB Conference on NHTSA's Five-Year Plan. Many participants recommended that there be a mechanism to comment on reports of workshops. They suggested that such a mechanism could even be by mail. HSRI personnel noted that it was their standard practice to disseminate drafts of workshop reports to participants for review and comment in the workshops they have conducted for NHTSA; this practice would continue to be followed for the present workshop.

Many participants expressed the desire to have more open-ended discussions rather than critiques of existing or proposed projects. One participant suggested a two-step process in which NHTSA solicited ideas and developed a research program including that input; the second step would be a meeting to provide researcher and user interchange. Participants agreed that more time should be set aside in future workshops to focus on new projects or research areas. They also agreed that more information on current projects should be provided in order to evaluate proposed future projects.

Finally, with respect to workshop procedures, panel members commented that receiving the project descriptions the evening before the workshop did not give them enough time to review the material and make detailed comments on each project. They recommended that project descriptions be mailed to participants in advance of future workshops to give an opportunity for more detailed comments. Also, several participants 
indicated that insufficient project information was provided and that the review of methods would have been facilitated by more detailed project descriptions.

Participants did suggest that the level of funding is likely to be low for 1983 when an inflation factor is taken into account.

\subsubsection{Pedestrian State-of-the-Art Safety Literature Review}

Although the title of this project refers to a pedestrian literature review, NHTSA resource persons noted the effort will include reviews of the bicycle and pupil transportation literature as well. The project is described as follows.

Pedestrian State of the Art Safety Literature Review (60K)

$$
\text { FY } 183-60 \mathrm{~K}
$$

\section{Summary/Overview}

This project will provide a state-of-the-art review of the pedestriansafety literature and develop an annotated bibliography of existing materials. The results of this review, including recommendations regarding future directions for pedestrian research, will be made available to the public.

\section{Purpose/Justification}

In the past, NHTSA has conducted only limited reviews of the pedestrian safety literature within the context of reaching a study's larger objective, e.g., developing countermeasures. An extensive review of this literature is overdue.

\section{Objectives}

The objectives of this study are to: (1) critically review the literature related to pedestrian safety; (2) develop an annotated bibliography; and (3) provide recommendations concerning pedestrian safety research needs.

\section{Method}

- Review the literature in selected areas related to pedestrian safety, e.g., literature in highway safety, experimental/developmental and motivational psychology; evaluation and training; urban planning. 
- Develop an annotated bibliography by including cross indices (e.g., subject, author).

- Provide a critique of the pedestrian literature review (e.g., in terms of scope, adequacy of methodology).

- provide suggestions on future program research needs.

\section{$\underline{\text { Results }}$}

A critical review of the pedestrian safety literature and an associated bibliography shall be made available.

\section{Application}

The state-of-the-art literature review will be made available to the public.

NHTSA intends for such literature reviews to occur on a periodic basis.

The two workshop groups were divided on this project. Group A generally viewed it as relevant and necessary. Participants in Group B, however, expressed strong reservations about the need for this project as currently proposed. Several members noted that almost all of the projects discussed previously involved literature searches. They believed that this project should either be incorporated into each of the projects requiring a literature review or be moved up in time to provide literature review support to the other projects.

Participants also questioned the need for a full-scale literature review since several were currently being conducted under other sponsorship. The participants noted four current literature reviews:

- Integrated Planning and Facilities Design for Pedestrians project for the Urban Mass Transit Authority (UMTA) at Iowa State University;

- Bicycle and Pedestrian Safety project for the Federal Highway Administration (FHWA) being done by Texas Transportation Institute and Northwestern Traffic Institute;

- Synthesis of Pedestrian and Bicycle Literature project by FHWA; and

- Pedestrian and Bicycle Safety Assessment project being done by Applied Science Associates. 
Participants suggested the proposed project coordinate the results of these literature reviews and update their findings in two to three years.

Finally, with respect to the need for this project, participants recommended that it be combined with the workshop project to provide groundwork for planning beyond 1984 as well as an update of the literature.

There were few comments made about the literature-review method within Group B. All participants agreed that if a full-scale literature review is done, it should carefully take into account all literature reviews currently being conducted. One participant noted that critiques of research are almost never performed in literature reviews; this project might provide for such an approach. NHTSA resource persons indicated that their literature reviews are modeled after the HSRI Drug Research Methodology project, which does contain critiques of research.

The sufficiency of the project's method was questioned by the participants in Group A. Three areas were of concern to panelists: the literature base itself, the methods of search, and the duration of the activity.

A need for focus in the literature-review activity was noted in this workshop group. It was pointed out that the Transportation Research Information System (TRIS) contains over 350,000 citations through 1978; ten to fifteen percent reflect the pedestrian area. The recommendation was made that NHTSA carefully specify criteria for selecting the literature for review. Participants did not think, however, that NHTSA should necessarily limit a search to pedestrian safety literature. It was pointed out that potential countermeasures are likely to exist in the literature of other fields. Examples included the conspicuity studies of Coast Guard search-and-rescue efforts as well as railroad and airline studies.

The participants cautioned NHTSA that traditional search methods would not be adequate to capture the information that is being produced. Most computer-based indices fall about three years behind current efforts due to technical lags in publishing. To be current, any literature search must be prepared to look at nontraditional literature sources. It was further 
pointed out that NHTSA's Highway Safety Literature (HSL) system has neither the funds nor the indexing capability to survive with the amount of information that exists. Other participants suggested a mechanism for locating foreign-technical reports (as well as translations) be considered for this project.

Members of Group A strongly recommended that NHTSA support this project as a continuing activity and not simply as a periodic effort. A continuous monitoring of the literature as well as decisions about when to update the review were seen as essential. Participants noted that substantial costs are involved in setting up a literature-review system. It was viewed as more cost-effective to set up the system once and leave it in place rather than dismantle it and reinvest the initial efforts at a later time. The workshop group recognized that problems could arise for NHTSA in contracting out such a project. Therefore, it was recommended that NHTSA begin efforts to make the literature review an in-house activity. The initial establishment and test of the literature review mechanism could be set up under the contracting system; updating would be done by NHTSA staff. Participants stated that this review is a library function of NHTSA but recognized that it will require additional funds and staff.

Finally, participants noted that however the literature review is accomplished, the end product should be useful for practitioners; information on how to apply the review or aspects of it should be made available. Furthermore, it was recommended that a dissemination component be written into the literature review project from the beginning in an effort to better reach the operational people. NTIS was not considered adequate; the viewpoint was expressed that most operational people do not know of it, and if they do, they do not have the funds to obtain the documents they need.

\subsubsection{Development and Field Test of Bicyclist Public Information and} Education Safety Messages (Project \#42)

The purpose of this project is to test safety messages developed under 
another NHTSA contract. Products will be made available for technology transfer. The project description follows.

Development and Field Test of Bicyclist Public Information and Education Safety Messages (400K)

FY 83 - 150K; FY $84-250 \mathrm{~K}$; FY $185-0$

\section{Summary/Overview}

Prior NHTSA research developed prototype public information and education safety messages for use with targeted groups of bicyclists. This effort will fully develop and test them for their effectiveness in an experimental setting. The output of this project will be safety message materials (posters, brochures, TV/radio spots, etc.) which will be made available for technology transfer.

\section{$\underline{\text { Purpose/Justification }}$}

A prior NHTSA research project developed prototype safety message materials (e.g., storyboards, pamphlets) aimed at selected bicyclist accident types (e.g., rideout-type accidents, wrong-way-riding accidents).

\section{Objectives}

The objective of this project will be to fully develop and test public information and education safety messages for their effectiveness in reducing the occurrence of selected types of bicyclist/motor-vehicle accidents.

\section{Method}

- Review the prototype messages and recommend, for government approval, from 5-8 messages for further development and test.

- Pretest the message contents for knowledge gain and behavior change.

- Develop up to five message contents into a form suitable for reproduction and mass media use.

- Develop a field test plan for determining the effectiveness of the messages.

- Implement the plan after government approval and assess the effectiveness of the messages. 


\section{Results}

Messages in a form suitable for mass media use will be available along with their accident reduction effectiveness.

\section{Application}

Messages shall be made available for technology transfer.

The workshop group generally supported this NHTSA-proposed effort. Participants viewed the project as relevant and necessary.

Critique of the study's method focused upon the first step described under method: "Review the prototype messages and recommend, for government approval, from 5-8 messages for further development and test." Participants recommended that NHTSA select and specify the messages for testing in the RFP, rather than expend the contractor's efforts in a search-and-review mode. The panel recognized that NHTSA has limited resources but pointed out that such a specification may actually save time and effort within NHTSA when it comes to evaluating the proposals in response to the RFP. Contractors noted that it is easier to write and cost a proposal when the RFP states what is to be produced and tested. It is likely that proposals in response to such an RFP will be more specific, thereby making NHTSA's evaluation process easier.

One participant noted that field tests of PI\&E messages are susceptible to the manner in which they are implemented. For example, in a field test conducted in several cities, variables among the cities are introduced, such as amount of effort expended and media cooperation available. In many cases, it is difficult to tell whether it was the messages or the manner of implementation that was effective. Several participants agreed with this observation, and the group as a whole recommended that if field tests are to be conducted in more than one location, NHTSA should continue its practice of having one contractor responsible for the implementation of the messages in all locations.

Also arising out of this discussion was the recommendation that one contractor be involved in the development of the messages to be field tested, so that the design of the products will be well-integrated. 
Several participants commented on the scheduling of the project. They recommended that this project and the project "Field Test Bicycle Training Program" be conducted simultaneously by moving the proposed project up to FY 82. It was suggested that products were being delayed with the current schedule. NHTSA responded that it would like to do that but is locked into the current schedule by funding priorities and allocations.

\subsubsection{School-Bus-Related Countermeasure Review and Update (Project} \#43)

This is the last $R \& D$ project reviewed in the workshop. It is described as follows.

School-Bus-Related Countermeasures Review and Update (60K) FY' 84 - 60K

\section{Summary/Overview}

Past NHTSA research developed and tested countermeasures based on several approaches (training, traffic-safety regulations, and public information and education safety messages) for reducing school-busrelated pedestrian accidents. In this study, one or more of the previously developed and tested countermeasures will be reviewed and updated as needed in light of recently analyzed accident information about the causes and problems associated with schoolbus-related accidents. These updated countermeasures will then be made available for technology transfer.

\section{Purpose/Justification}

Based on a recent NHTSA research project which, in part, analyzed accident data pertaining to school bus accidents, existing NHTSA countermeasures may have to be revised.

\section{Objectives}

The objective of this project is to review previously developed school-bus-related accident countermeasures and to revise them as needed in light of more complete accident information.

\section{Method}

- Review past study which provides additional data regarding school-bus-related accidents. 
- Review previously developed and tested countermeasures and determine whether the training procedures, countermeasures advice, and traffic safety-regulation information remain viable.

- If warranted, develop a countermeasures plan for updating each of the previously tested countermeasures.

- After government approval, implement the needed changes for one or more of the countermeasures.

\section{Results}

This project will yield one or more updated school-bus-related countermeasures (e.g., PI\&E safety messages).

\section{Application}

One or more updated countermeasures (regulation, messages and/or training packages) will be made available for technology transfer.

The focus of this project is on pedestrian-related school bus accidents. The study is linked to a current NHTSA project, "Analysis of School-BusRelated Pedestrian Accident Types" (see Block 31 in Figure 2-1). That project involves three countermeasures:

- training,

- model traffic safety regulations, and

- school bus driver pamphlet.

It is anticipated that the current project will produce more information on school bus accident types. The proposed project will use the information from the current effort to determine appropriate countermeasures and modifications.

Participants generally agreed with the relevancy of the project. Several participants questioned the size of the sample used to develop the countermeasures. It was reported that the countermeasures were based on a study of forty-six school-bus/pedestrian accidents. Participants felt that this was a very small sample on which to base the selection of countermeasures. They generally agreed that if the proposed project was to be worthwhile, NHTSA should increase the number of schoolbus/pedestrian accidents to be analyzed. One participant suggested indepth accident investigation as a useful tool for learning more about the 
causes of such accidents.

Arising out of this discussion, several participants questioned whether the school-bus/pedestrian accident problem was large enough to warrant further research. It was explained that while the school-bus/pedestrian accident problem is not large in number, almost every accident is severe. A participant pointed out that in one jurisdiction, three-quarters of the school-bus-related fatal accidents involve pedestrians. Given the severity of these accidents, participants agreed the research was worthwhile.

Several participants had comments on the countermeasures being developed. They noted that in approximately fifty percent of the schoolbus/pedestrian fatalities, the victim was hit by the school bus itself. It was their opinion that more effective countermeasures could be directed at the bus driver. These participants pointed out that the weakest countermeasure component (i.e., pamphlets) were directed at bus drivers. The group generally agreed and recommended that countermeasure programs be directed at the bus driver rather than the children.

Practitioners in the group, however, expressed concern that the countermeasures for study here should go beyond driver-oriented training. They suggested broadening the program to give managers some flexibility in countermeasure implementation. Three participants strongly suggested that pupil conduct on buses be investigated as a causal factor in school bus accidents, particularly as it affects the driver of the bus.

One participant also questioned the amount of countermeasure activity focused on other drivers. NHTSA explained that model traffic regulations, such as vehicle liability rather than driver liability, were being developed. Panel members agreed that if these regulations could be legally enforced, they would be reasonable countermeasures.

Concern was also expressed over the timing of the project. Participants noted that there was a two-to-three-year break between this study and its link in the NHTSA program. Several remedies were suggested; these included starting up the proposed project sooner, delaying the start of the linking project, or combining the two projects into one research effort. The group recommended having the two projects closer in 
time to each other.

A final comment by participants urged NHTSA to expand its review of school bus/pedestrian countermeasures beyond its own products. One participant pointed out that states have developed a variety of countermeasures including training programs and PI\&E materials. The group recommended that NHTSA conduct an inventory of what the states are doing through their 402 planning function. In so doing, a survey could be avoided.

\subsection{Additional Research and Development Topics}

A major issue raised by participants was a need for the development of enforcement countermeasures in the pedestrian/bicycle area. Participants noted that the only enforcement countermeasure seen in this area has been the model ice cream vendor ordinance. NHTSA responded that except for the model traffic ordinances, enforcement countermeasures are not effective, especially in the pedestrian area. The lack of enforcement of existing jaywalking ordinances was cited as an example. Participants with enforcement background and experience responded to NHTSA's explanation by saying that many police agencies would be more than happy to enforce pedestrian laws, but to enforce the law, a minimum level of support is needed from both the public and the police officer doing the enforcement. Other members of the group strongly agreed and recommended that NHTSA include increasing support for pedestrian and bicycle laws among the public and police officers as an objective of its PI\&E campaigns. It was believed that by doing this, an environment could be created where enforcement of these laws will be supported. Several participants supported this recommendation with specific comments. One participant pointed out that in one state, bicycle laws had been more effectively enforced because offenders were referred to instructional clinics rather than to court. A PI\&E campaign in advance of the program raised support from the police and the public. Another participant observed that the greatest level of bicycle enforcement often takes place in smaller cities and towns where it is easier to obtain public support. 
Another issue raised by one participant was the need for NHTSA to pay more attention to design solutions for pedestrian and bicycle safety problems. It was suggested that perhaps NHTSA could convene design consultants to brainstorm about specific problems. NHTSA personnel responded that this is being done to an extent by FHWA and is not within the purview of NHTSA. Participants did, however, strongly urge NHTSA to sponsor a mechanism for coordinating efforts with other federal agencies. Panel members felt that a lack of communication about the various activities directed at one problem area allowed too many unnecessary gaps to arise. A coordination of these efforts would allow for filling in the picture of the problem and better identifying safety goals in the area.

Several participants. commented that the most obvious countermeasures are public information and education campaigns. As a result, almost all projects in this area appear to depend on these as their primary countermeasures approach. Participants agreed that NHTSA should look for mechanisms other than PI\&E campaigns. NHTSA resource persons agreed that PI\&E campaigns were the most readily identifiable countermeasures in this area and allowed that past efforts have relied quite heavily on this type of countermeasure. It was suggested that NHTSA become more sensitive to the use of PI\&E campaigns by establishing criteria for when to use such countermeasures.

\subsection{Summary}

Workshop participants generally supported the relevancy and necessity of most of the projects proposed by $R \& D$. The sufficiency of methods to achieve safety goals was, however, frequently questioned. Participants urged NHTSA to be sure that target groups, methods, and objectives of projects were carefully delineated. Project-specific suggestions were made. In some cases, funding levels were viewed as too low to accomplish the stated objectives. Concerns about the scheduling of projects were also raised; some projects were seen as being too far removed in time from their linking project within the program area. 
A more general concern was raised with regard to the focus of countermeasure activity within the pedestrian, bicycle, and pupil transportation program area. Participants noted that there has been extensive use of the PI\&E countermeasure approach and suggested that NHTSA extend the scope of the countermeasure activity in this area. Consideration of more enforcement activity was recommended. Greater interface among government agencies (for example, FHWA for road design) was strongly recommended by the workshop panel as a strategy for bringing about a more complete approach to the problems addressed by this area. Extending literature searches on selected topics (for example, conspicuity measures) beyond the highway safety area per se was also suggested as being a potentially useful activity. 


\subsection{TRAFFIC SAFETY PROGRAMS}

Working Sessions Two and Three were focused upon the projects proposed by the Office of Traffic Safety Programs (TSP). Two projects were reviewed in the second working session: Countermeasure Support and Implementation, and Child Traffic Safety Club Demonstration. The discussion for the third working session was focused upon the topic of technology transfer and is presented in Chapter Five.

\subsection{Background}

The two TSP projects reviewed in the second workshop session begin with FY 1982 and extend through 1984. Both projects take into consideration all three areas of pupil transportation, bicycle, and pedestrian safety.

The primary focus of the two projects reviewed here is on demonstration activity.

\subsection{Discussion}

As in the first working session, participants addressed the relevancy and necessity of each project to overall program objectives. The sufficiency of the project in achieving its safety goals was again considered.

\subsubsection{General Comments}

Panel members generally supported the relevancy and necessity of the two projects reviewed during the second working session. The sufficiency of the projects' methods for accomplishing the stated objectives was, for the most part, considered appropriate. Concerns about funding, however, were expressed.

Several participants queried NHTSA concerning how they arrived at the estimated funding levels for the proposed projects. It was explained that 
projects were proposed for two to four years into the future, and best estimates made. NHTSA resource persons indicated that because specific work statements had not yet been developed, these estimates would not be highly accurate; for projects closer in time to the present, projects were costed out in terms of manhours and overhead.

From this discussion, many participants asked if RFPs in the future could reflect projected dollar amounts. They indicated that this would make the bidding process more efficient and help to eliminate cost overruns. NHTSA personnel responded that in the last few years, selected RFPs have contained this information. The contracts office looks at these contracts over the course of their performance and compares them to other contracts in terms of cost. NHTSA resource persons indicated that this had not been done previously due to a belief that not putting dollar amounts in RFPs gets the work done for less money. Several participants pointed out that this was an unproven hypothesis.

Participants also questioned the reasons for the low priority placed on pedestrian and bicycle research. Explanations such as the lack of amenability to solutions or the lack of hardware countermeasures were discussed. Many participants believed the biggest single reason for the low priority was the lack of effective advocates for pedestrian and bicycle research. Participants agreed that the advocacy function of pedestrian/bicycle researchers and users needed to be increased.

With regard to specific program content, there was a general concern about the criteria for countermeasure implementation. Participants noted that there are no specific criteria for "letting a countermeasure loose on the world" or for "killing it." Participants suggested that it would be more useful to and more economical for the states if they were kept better informed about the effectiveness of countermeasures. Suggestions for possible measures of effectiveness included knowledge change, behavior change, accident rate, or a combination of these three factors. The panel recommended that NHTSA establish specific criteria to determine at what point countermeasures are to be transferred to the states.

Project-specific comments follow. 


\subsubsection{Project-Specific Comments}

TSP project descriptions were provided to participants by NHTSA at the workshop. These descriptions are presented in each subsection below; group comments follow. The project numbers refer to numbers on the project flowchart in Figure 2-1 (see Section 2.0).

\subsubsection{Countermeasure Support and Implementation (Project \#1)}

This is not one distinct project but instead represents an ongoing effort. It is intended to be a series of mini-demonstration projects to support the implementation of countermeasures and other products produced by $R \& D$. It is not intended to be a large-scale demonstration like the Alcohol Safety Action Program (ASAP) or the Miami Five-Year project. Instead, the purpose of the project is to "bridge the gap" between the time when products come out of $R \& D$ and when they are handed over to state and local agencies for implementation. During this time, it is anticipated that implementation problems such as cost, acceptability, and logistics can be identified and resolved. Practitioners will be provided assistance in making countermeasures more appropriate to their locality when necessary. The project is described below.

Title: Countermeasure Support and Implementation FY 1982 - 100K; FY 1983 - 250K; FY 1984 - 250K

CTM: Kurrus

\section{Summary/Overview}

Each year nearly 8,000 pedestrians, 1,000 bicyclists, and 100 school bus passengers are killed in motor vehicle crashes. Past research has analyzed the pedestrian and bicycle problem, and accident types have been identified. Countermeasures for many of these accident types have been, or are being, developed and field tested. State and local program implementation efforts will be supported for those countermeasures needing further demonstration, evaluation, and/or modification. Emphasis will be on those products lacking documenting data, or deemed difficult to implement for reasons of cost, acceptability, logistics, etc. 


\section{Purpose/Justification}

Research development countermeasures often encounter real-world impediments to implementation and/or effectiveness. This project will alleviate or mitigate many of those hindrances by supporting State and local countermeasures implementation, demonstration, and evaluation.

\section{Objectives}

The objectives of this project are to:

1) Demonstrate and evaluate selected countermeasures in real-world settings,

2) Support State and local efforts to implement difficult countermeasures through unique strategies and assistance, and

3) Modify countermeasures and approaches based on actual State or local implementation experience.

\section{Method}

In FY 1982, the PEDSAFE Rural training program will be supported through further development and refinement of printed material and films, and will be demonstrated and evaluated in a real-world setting. In FY 1983, conspicuity standards will be tested for public acceptance and effectiveness through model ordinance support as well as a possible demonstration. In FY 1984, bicycle countermeasures will be demonstrated and evaluated in a real-world setting. Additionally, other countermeasures, such as model ordinances, will be supported as necessary through development of selective demonstrations, legislative packages, or other program materials development unique to the locale and situation in question (e.g., PI\&E packages, curricula).

\section{Results}

The results of this program will be an inventory of countermeasures according to their feasibility, acceptability, effectiveness, and unique or difficult aspects. Further, various implementation strategies and support packages will be available for those countermeasures found to have implementation difficulties.

Participants in Group B had a number of questions about this project. Many wanted to know the difference between it and technology transfer. NHTSA personnel explained that in technology transfer the products have been proven effective and accepted, while the proposed project deals with 
products that may not have been tested sufficiently before coming out of $R \& D$ or may contain "bugs" that have not been worked out. Rising out of this explanation, several participants wanted to know how interchangeable the funds in this project and technology transfer would be. NHTSA personnel responded that they envisioned the two funds to be interchangeable, depending on specific needs at any given time. They emphasized that the differences between the two projects were subtle and that taking funding from either project for either purpose could be justified.

Several participants also asked for a clarification of the relation between the proposed project and state 402-implementation funds. It was explained that the project's funds can be used in conjunction with state 402 funds, or the project can fund state operational programs in their entirety. A NHTSA resource person pointed out that 403 money can be used for evaluations at the state level; a justified use of these funds would be to further document the effectiveness of an $R \& D$ product at the state level. For example, the testing of a model traffic regulation in an operational setting would be a justified use of project funds.

One participant strongly cautioned NHTSA, that if they intended to use funds from this project in conjunction with 402 funds, they should clarify "to the Nth detail" the interaction of the two funds. It was pointed out that this has been a problem in some states.

Several participants also questioned whether the funds from this project could be used in conjunction with the new innovative grant program. Legislation has recently been enacted authorizing the award of grants to state and local governments and private organizations for innovative projects. This legislation allows NHTSA to formulate "need statements" to which agencies and organizations may respond. NHTSA resource persons noted that the use of this legislation had not been contemplated, but it was conceivable that it could be used.

Participants also had questions about the mechanics of obtaining support under the proposed project. Several participants wanted to know if funding from this project was available for the implementation of any NHTSA 
pedestrian or bicycle research product. NHTSA replied yes, as long as it is a product of NHTSA research. Other participants wanted to know if the funding was for contractors or for local communities. NHTSA resource persons replied that it could be either, depending upon the characteristics of a particular project. Finally, participants wanted to know the procedure for obtaining funding from the proposed project. NHTSA resource persons indicated that the exact procedure had not yet been established but that it could be in the form of either a direct NHTSA solicitation or a particular request from a contractor.

One participant asked if any specific demonstration projects had been identified for funding from this project. NHTSA resource persons indicated that there were two efforts likely to be funded through this project:

- the New Jersey Willy Whistle project; and

- the use of a contractor to promote and sell a model ordinance that has not been fully documented (i.e., no proof of accident reduction during $R \& D$ stage).

A final comment by participants pertained to the output of the demonstrations funded under this project. One participant wanted to know whether NHTSA planned to publish a single document that would combine the results of all the demonstrations conducted under this project. NHTSA resource persons replied that this was not planned; each demonstration would be reported separately and be available as part of NHTSA's inventory of materials. A NHTSA resource person indicated that as a separate project, TSP is developing a 403-project publication. The publication will have two volumes: the first volume will contain brief summaries of all TSP projects in each program area; the second volume will contain detailed descriptions (i.e., paragraphs) of individual projects. It is anticipated that this document will be available in March 1981 and will be updated annually.

Participants in Group A generally viewed the project as appropriate. No comments with regard to method were offered. 


\subsubsection{Child Traffic Safety Club Demonstration}

The project description for this study follows.

Title: Child Traffic Safety Club Demonstration

FY 1984 - CTM: Unknown - Estimated Cost: $100 \mathrm{~K}$

\section{Summary/Overview}

In the U.S. thousands of children are killed or injured each year in pedestrian motor-vehicle accidents. A small but important percentage includes children from one to five years of age. It is anticipated that NHTSA development and test of a pre-school Child Traffic Safety Club will show success in changing childrens' and parents' behavior regarding traffic situations. The Child Traffic Safety Club concept will then be demonstrated and evaluated in a real-world setting to assess its feasibility, acceptance, and effectiveness in reducing pre-school pedestrian accidents.

\section{Purpose/Justification}

European experience has found that Child Traffic Safety Clubs can be successful in changing both child and parent behaviors that contribute to accident situations. This project will seek to establish that Child Traffic Safety Clubs are feasible and useful for addressing the needs of child pedestrians in the United States.

\section{Objectives}

1) Develop and implement a Child Traffic Safety Club in a State or local jurisdiction,

2) Demonstrate that Child Traffic Safety Clubs are feasible, acceptable, and effective in changing parent and child behaviors, and

3) Determine the effectiveness of Child Traffic Safety Clubs in reducing pre-school pedestrian accidents.

\section{Method}

In FY 1984, a demonstration site will be selected, and a Child Traffic Safety Club and evaluation plan implemented. The Club will be operated for at least one year, with pre, mid, and post program assessments of knowledge, behavior, and accidents being recorded. Program obstacles and acceptability will be documented, with possible extension of the operational phase dependent on these assessments and any modifications necessary. Following the operational phase, an evaluation of the program's feasibility and usefulness (in addition to knowledge, behavior, and accident changes) 
will be made. A $24-30$ month project duration is anticipated.

$\underline{\text { Results }}$

The results of this project will be:

1) A determination of the feasibility, acceptability, and effectiveness of Child Traffic Safety Clubs as a program approach,

2) A version of the Child Traffic Safety Club, with supporting materials and documentation, determined to be best for State and/or local implementation.

This project is linked to a current $R \& D$ project to develop the Child Traffic Safety Club (CTSC) (see Block 26 in Figure 2-1). The proposed project will implement the program currently being developed. A set of materials to be mailed to parents is now being designed. There is some sentiment for expanding the program to day-care and preschool programs, but that direction is unclear at this time. The materials being developed are based on those used in the European Child Traffic Safety Clubs.

Participants were generally supportive of an effort of this type. However, there were indications that this kind of work is already underway. One participant reported on a university that has received state 402 funds to develop a Child Traffic Safety Club for day-care centers. NHTSA resource persons were unaware of this activity. It was recommended that NHTSA determine how broadly this concept is being developed at the state level, and if appropriate, coordinate the development of the national program with the various state programs.

One participant questioned whether it would be redundant to allocate so many resources proving the success of the CTSC in the United States, given a successful European experience. NHTSA pointed out that while the Eurpoean experience is relevant, a number of different demographic and social variables exist. Such variables may result in the concept and materials not being transferrable. Thus, the concept and materials need to be tested here. On the whole, the group supported the objectives of this project, provided NHTSA was careful to coordinate its efforts with activities being done in the states. 
Another question raised by participants was how much testing of the CTSC was to be done in the current project. NHTSA resource persons responded that it planned to have a two-year field test as part of the current project to assess behavioral changes as well as accident reduction. Several participants noted that if such an extensive field test was being done, the proposed project may not be necessary. NHTSA responded by saying that it expects the project will be needed to assess large-scale implementation of the CTSC concept. NHTSA was cautioned to be sure the evaluation of the project currently underway in $R \& D$ is satisfactorily completed before implementing the TSP project.

\subsection{Additional TSP Topics}

Two additional issues were raised for the consideration of TSP by workshop participants. It was noted that the proposed projects do little to tie in with education in the public schools. The proposed projects are not targeted to direct instruction, while educational research suggests that that method is the most effective. The public school system was recommended as a natural delivery system for safety training.

A broader recommendation, strongly supported by the group, was that NHTSA improve its efforts for determining states' activities in this program area. Furthermore, a mechanism is needed to inform other states about these activities. Several participants noted that there were some very fine programs at the state level that need to be publicized beyond the state in which they are being performed. This topic was discussed in more detail when the group discussed technology transfer.

\subsection{Summary}

Workshop participants were generally in agreement with the relevancy, necessity, and sufficiency of the projects proposed by TSP. Questions were raised regarding the mechanics of funding under the "Countermeasure Support and Implementation" project, and panel members urged NHTSA to clearly specify how funds would be administered under that project. More generally, the workshop group was concerned about the lack of criteria for 
releasing a countermeasure to the states and local communities. It was recommended that NHTSA establish specific criteria for countermeasure implementation. 


\subsection{TECHNOLOGY TRANSFER}

The final working session was focused upon technology transfer. The workshop panel discussed the topic generally as well as specifically with regard to the proposed technology transfer project.

\subsection{Background}

NHTSA's technology transfer efforts in the pedestrian/bicycle/pupil transportation area are housed within TSP. Current efforts are geared toward improving the dissemination of materials below the levels of the Governor's Highway Safety Representative and the NHTSA regional office. These efforts are focused in two directions:

- disseminating NHTSA's products to the state and local governments, and

- encouraging the actual use of the product by the intended users.

FY 1981 projects include the promotion of the Pedestrian Accident Reduction (PAR) Guide, the Computerized Accident Typing (CAT) Guide, and the Manual Accident Typing (MAT) Guide through a number of means. These include brochures and pamphlets as well as workshops to introduce the PAR manual and the new pedestrian safety film "Willy Whistle." The specific technology transfer activity presented for review by TSP at the workshop begins in FY 1982 and continues through FY 1984. All three areas of pedestrian/bicycle/pupil transportation safety are considered within the project.

\subsection{Discussion}

The workshop panel again focused upon relevancy and necessity in considering technology transfer efforts in the pedestrian/bicycle/pupil transportation program area. Sufficiency of effort was also considered. 
Most comments in this working session were of a general nature.

\subsubsection{General Comments}

The workshop group generally viewed the technology transfer efforts as highly necessary and relevant. The activity, however, was viewed as disjointed rather than systematic. Participants suggested that too of ten NHTSA's efforts are focused on a one-time promotion of NHTSA materials. Little effort was seen for gathering relevant information developed elsewhere. The need to provide material on a continual basis was also noted. Participants pointed out that there are two aspects to the technology transfer process: (1) the ability to capture information, and (2) the ability to make the information available to potential users.

A primary issue raised by workshop participants was the need for NHTSA to include in its technology transfer function a mechanism for identifying and publicizing work that is being done at the state and local level. The group noted that much information is being produced under the sponsorship of state, local, and private funds. Participants questioned whether a NHTSA central office was set up to identify, collect, and index such material in a structured way. NHTSA resource persons responded that materials were collected by the Office of State Program Assistance and forwarded to the National Project Reporting System. However, these projects are limited to 402-funded activities. One participant further pointed out that when asked to identify 402-produced products one-andone-half years ago, NHTSA personnel could not respond. The establishment of a structured system for indexing and storing information was seen as valuable particularly for operational people with limited resources.

Group members recommended that NHTSA act as a clearinghouse for information or projects being done at the state and local levels. They stressed that NHTSA does not have to produce a formal document. Regular updates, perhaps in newsletters to NHTSA's constituencies informing them about what is happening at the state level could be provided. One NHTSA resource person indicated there may be some problems with NHTSA becoming a clearinghouse for state projects since 
many of these programs seem counterproductive to NHTSA goals; such a function might be seen as an implied endorsement of such projects. When questioned why it was believed that many state programs were counterproductive, NHTSA resource persons identified a lack of adequate evaluations as the primary methodological fault of state and local programs. One participant advanced the opinion that state and local people may be more concerned with evaluations of the effectiveness of programs within their own community rather than with its implications for the traffic safety community as a whole. NHTSA resource persons indicated that one of the outputs of a current pedestrian and bicycle project will be the development of an assessment strategy to aid state and local agencies in evaluating the safety relevance of their programs. They said that if better evaluations are done on these programs, it may be feasible for NHTSA to act as a national clearinghouse for such project findings. Many participants continued to stress that given the large amounts of 402 funds being spent on local projects, NHTSA should still publicize local projects, if only to inform other states and local agencies of previous mistakes.

Participants stressed that the second aspect to the technology transfer problem was making information available once it was captured. They noted that this involved identifying potential users, the users' needs, and a potential delivery system. There was a comment that projects are not getting to the people who need them. The identification of potential users was seen as the essential first step in this process. This group is likely to include local and regional highway safety offices as well as persons not necessarily within the traditional highway safety community. For example, teachers, police officers, and community organizations could all be potential users at some point and are frequently not captured within the traditional highway safety network.

The second step suggested for making information available to user groups was to identify the users' needs. This would aid in determining how best to present information. For example, one participant suggested that a very abbreviated description of the project, its objectives, methods, 
and results along with an identification of persons to contact for further information would be useful to practitioners, especially those with few resources. Other participants suggested that making work products available as well as the project descriptions would be a valued effort. Participants noted that while project reports may be input regularly into the system, products are not. NHTSA resource persons did note that the submission of such material is currently done on a voluntary basis. The panel suggested that it was exactly those kinds of materials that were viewed as useful at the local level. It recommended that NHTSA consider gathering such on a routine basis.

Other participants also encouraged NHTSA in their role as advisor to state and local programs to give technical assistance to communities that are setting up programs as well as providing evaluation instruments. NHTSA responded that this function is anticipated under the countermeasure support and implementation project. Related to this, panel members urged NHTSA to assist in the evaluation of state and local programs by assisting in the funding of these functions. NHTSA resource persons agreed that this would also be an appropriate function of the countermeasure support and implementation project.

Finally, participants emphasized the need for a systematic and continuous system of delivery for reports and work products. Several participants pointed out that they have had trouble locating the appropriate person in NHTSA to contact for specific information. It was recommended that NHTSA establish an information referral system to enable users to readily contact the person who can provide the information.

Participants also expressed concern that the current system misses many potential users, especially on the local level. As noted earlier, these include groups not found within the traditional highway safety network (e.g., teachers, PTA groups). Participants further pointed out that such groups are not likely to even be aware of the highway safety network or how it works. The panel acknowledged that it is probably the responsibility of the Governor's Representative or the NHTSA regional offices to provide such information. However, concern was also expressed 
that these offices themselves are probably in need of advice and materials for getting to the local people. The workshop group suggested that there is a need for a link to the local level to let those persons know what safety information exists and how to obtain it.

Participants also recommended that the delivery system provide material on a continual basis rather than on a one-time only basis. Participants noted that while products have been available upon being developed, they seemed to disappear after the initial promotion. It was recommended that materials be placed in an information system where they could be obtained at a later point in time.

A third delivery system issue raised by the workshop was the timeliness of NHTSA releases of research findings. Some participants believed that state and local users would be better served if preliminary results were released as research projects progressed. The release of specific countermeasures at the time of their identification rather than after extensive field testing was one suggested example. Many other participants, however, cautioned against the early release of results, noting that it was exactly that practice that has caused NHTSA trouble in the past. Large amounts of resources are likely to be spent on countermeasures of unproven effectiveness. When the countermeasures appear to be ineffective, the backlash potential is great.

The workshop panel strongly recommended that NHTSA establish a clearinghouse or central office to gather and disseminate information on. a routine basis. Panel members suggested this would make the process more consistent and less fragmented. It was noted that clearinghouse technology exists at a sophisticated level. Participants suggested the dissertation distribution system as a model. Both the Health and Human Services clearinghouse and the national clearinghouse for drug abuse information were pointed out as examples of federal agency clearinghouse systems. One participant suggested that if a NHTSA clearinghouse system was to be effective, NHTSA would somehow have to take the reproduction process back into the agency. It was noted that currently NHTSA has no control over the reproduction of materials. 
The workshop panel also suggested that NHTSA make use of existing networks to both disseminate information and to alert individuals about available material. Participants urged NHTSA to work more closely with organizations such as the PTA, Kiwanis, or the JCs to use the systems already in place. Publication of information in journals and magazines aimed at these particular groups (police and government planners were mentioned specifically) was one strategy proposed.

Greater use of libraries was also recommended. Participants, for example, noted the relative ease of obtaining an abstract of most dissertations through the use of a library; the same could not be said for NHTSA reports. It was noted that every state has at least one library designated as a Repository Library for federal documents. NHTSA reports, however, do not always go there. Participants asked whether that could be changed by NHTSA.

Finally, participants posed contracting as a strategy for product dissemination. The Consumer Products Safety Commission (CPSC) approach to film distribution was described as an example. CPSC contracts with a private firm to reproduce a film and distribute it by selling it at a reasonable profit. CPSC does not compete with the firm by distributing the film itself. The panel suggested that NHTSA consider having contractors responsible for the dissemination process.

Project-specific comments follow.

\subsubsection{Project-Specific Comments}

The description for the technology transfer project follows.

Title: Technology Transfer FY 82, 83, 84-CTM: Kurrus - Estimated Cost: $75 \mathrm{~K}$ p/yr.

\section{Summary/Overview}

Each year nearly 8,000 pedestrians, 1,000 bicyclist, and 100 school bus passengers are killed in motor vehicle accidents. Past research has analyzed the pedestrian and bicycle problem, and accident types have been identified. Countermeasures for many of these accident types have been developed, tested, and evaluated, and are currently available for utilization by State and local programs. Other 
countermeasures are being developed or tested, and will be available in the next few years. This project will provide, on a continuing basis, the transfer of research products, technical information and support materials to State and local jurisdictions. Strategies for the actual transfer of products and materials will be developed as the products become available, but will consist primarily of:

1) development of instructional, promotional, and support materials and documentation,

2) conducting workshops, meetings, and orientations,

3) creation of inventories for distribution, and

4) utilization of a communications/support network with State and local coordinators and key persons.

\section{Purpose/Justification}

Research-developed countermeasures can result in knowledge and behavior changes that can in turn reduce pedestrian, bicycle and pupil transportation accidents. Transfer of these countermeasures and information ensures that State and communities are informed of the effectiveness and availability of these products.

\section{Objectives}

The objectives of this project are to:

1) Transfer products and information to the States and local jurisdictions in a timely fashion.

2) Effect the utilization of these products and materials in State and local safety programs.

Method

In FY 1982, the following products will be available for transfer:

- Model Regulations and Public Information for Rural/Suburban Pedestrian Accidents

- Manual and Computer Accident Typing Systems for Bicycle Accidents

- PEDSAFE - A K-12 training program for rural accident types

For FY 1983: 
- Standards for Conspicuity Enhancement for Pedestrians

- An Assessment Methodology for Use in Evaluating State, Local, and Private Pedestrian Safety Programs

- A Tested Parking Setback Ordinance

For FY 1984:

- Dismounted Motorist Regulation, with supporting PI\&E materials

- Right-turn-on-red countermeasures (if warranted by research)

- Bicycle Accident Countermeasures

The strategies for actual transfer of these products will be developed in the year prior to their availability. Transfer methods will follow those techniques outlined previously, and will seek to be consistent with real-world problems, priorities, and acceptability.

\section{$\underline{\text { Results }}$}

It is anticipated that the technology transfer of countermeasures and technical information will result in greater awareness of effective program measures, increased utilization of countermeasures, and positive knowledge and behavioral changes, resulting in safety programs with greater accident reduction potential.

The workshop panel supported this project as both relevant and necessary. The title was, however, viewed as "inappropriate" for NHTSA's purposes. Suggested alternative titles included information dissemination, knowledge utilization, or knowledge transfer. The sufficiency of the project was questioned. The workshop group expressed concern that the project was underfunded.

A number of points were raised with regard to the project's method. Participants expressed the view that the project appeared disjointed, and a more systematic effort was necessary. For example, participants saw a need for NHTSA to have the target groups of this technology transfer effort specified. A systematic effort to identify where and how these groups get their information is also required. Participants did note that the "creation of inventories for distribution" stated in the project is a step in this direction. 
The panel also cautioned NHTSA to be sure a delivery system is in place before any marketing or promotion of products occurs. As one participant noted: if you announce something is available, then you have to provide it. Several participants suggested that to do otherwise greatly increases the potential of a "blow back."

The panel generally supported the NHTSA workshop approach for explaining new materials and products. One participant noted that it is especially useful to the operational people to have the contractor present with the NHTSA resource people at such workshops. Participants indicated that there are usually three levels that a product must go through before it reaches the user:

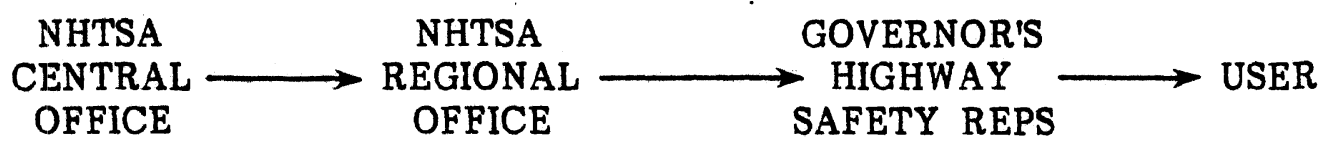

These participants thought that something was often lost in the translation. The workshop strategy allows for cutting out the middlemen. This approach was viewed as allowing for more in-depth questioning on the implementation of new products. It was supported by other participants who noted that other federal agencies (e.g., the Department of Energy) have provisions in their contracts for such efforts on the part of the contractors. Another strategy suggested was to have contractors identify potential users of the research results as well as ways of reaching those users as a specific contract task. While the workshop approach was supported, NHTSA was also urged to be sure that materials transferred in workshops are placed in an information system as well to provide for their availability at a later time.

Finally, the panel suggested NHTSA clearly define the function to be carried out through the technology transfer process. It was noted that differences exist between the dissemination of a technical report, the marketing of a product, and the delivery of a product. These differences have implications for the specific strategies that are used to accomplish the transfer. 


\subsection{Additional Technology Transfer Topies}

Panel members urged NHTSA to study the process of technology transfer in order to improve its own methods. Several participants noted that an understanding of one's audience and how it is affected by particular messages is critical. NHTSA resource persons responded by saying that they would like to do research in this area in the future but attempts to propose contracts of this kind have received little support. Group members strongly recommended that research in this area is needed now. They added that unless NHTSA puts forth this kind of effort it will continue to have a low return on its technology investment.

\subsection{Summary}

The workshop panel viewed NHTSA's technology transfer efforts as extremely necessary and relevant. A more systematic and continuous effort, however, appears to be needed; NHTSA's efforts were characterized by panel members as too often being of a "one-time" nature. Participants reminded NHTSA that there are two aspects to the technology transfer problem: the ability to capture information and the ability to make that information available to potential user groups. Panel members were especially concerned about the lack of identification and publication of work being done at the state and local level. Concerns about many potential users, again on the local level, being missed by the current system were also expressed. The establishment of a clearinghouse for the gathering, indexing, and dissemination of information was strongly recommended to NHTSA. Participants also urged NHTSA to take advantage of existing networks for the dissemination of information. Examples of such networks include professional organizations, professional journals, as well as public and university library systems. NHTSA was urged to examine already existing dissemination systems in both the public and private sector as models for a NHTSA information dissemination system. 


\subsection{CONCLUSIONS AND RECOMMENDATIONS}

The Problem-Behavior Workshop represents part of NHTSA's efforts to conduct periodic conferences to review technical developments, new information, and changing state and local needs in terms of traffic safety priorities. The purpose of this workshop was to develop specific recommendations for the planning and implementation of NHTSA research, development, and demonstration projects in the program area of Pedestrian, Bicycle, and Pupil Transportation Safety.

Workshop participants represented both the practitioner and research communities. They were provided an opportunity to review in-depth specific program elements. Two working groups participated in a series that dealt with the following topics:

- Research and Development Projects,

- Traffic Safety Programs Projects, and

- Technology Transfer.

\subsection{Research and Development Projects}

The nine projects proposed by Research and Development (R\&D) were reviewed by workshop participants in the first working session. These proposed efforts were distributed across the three areas of pedestrian, bicycle, and pupil transportation safety. Participants addressed the relevancy and necessity of each project to the overall program objectives; the sufficiency of the project in achieving safety goals was also considered.

For the most part, participants supported the relevancy and necessity of the proposed projects. Many panel members, however, reported difficulty in adequately assessing the objectives and methods of the projects under discussion, since many were contingent upon ongoing projects whose results were not yet determined. These participants stated that a clear 
understanding of the research upon which the proposed projects are based is needed to discuss relevancy and necessity.

Concerns were generally directed at the sufficiency of the projects' methods for accomplishing the stated objectives. Participants commented that methods appeared vague in most project descriptions. Clearer delineation of target groups, strategies for testing, as well as study objectives was seen as needed. The panel urged NHTSA to specify clearly the focus of the proposed projects.

Disappointment regarding funding level was also expressed. Panel members viewed the funding for many projects, as well as for the entire program area, as too low to accomplish the safety objectives.

Panel members argued that NHTSA should adopt a broader approach to the pedestrian, bicycle, pupil transportation safety problem. They noted the extensive use of the PI\&E countermeasure approach and suggested that NHTSA extend the scope of the countermeasure activity in this program area. Participants suggested the development of more enforcement countermeasures. Some participants noted that the only enforcement countermeasure they had seen in this area has been the model ice cream vendor ordinance. It was recommended that NHTSA include increasing support for such laws among its PI\&E campaign objectives as a first step in that direction.

A second issue raised was the need for greater attention to design solutions to the pedestrian and bicycle safety problem. While participants recognized that this area was not within the purview of NHTSA per se, they used it as an example of the need for interaction among agencies in the exchange of information. An emphasis upon treating the problem as a whole was expressed. Participants suggested that a lack of communication about the various activities directed at one problem area allows too many unnecessary gaps to arise; a coordination of these efforts among agencies would allow for filling in the picture of the problem and better identifying safety goals in the area. The group strongly endorsed the concept of interagency exchange of information. Panel members urged NHTSA to take the lead in sponsoring a mechanism for coordinating efforts with 
other federal agencies, including, for example, the Federal Highway Administration, Health and Human Services, and the Department of Education.

\subsection{Traffic Safety Programs Projects}

Two of the three proposed Traffic Safety Progams (TSP) projects were reviewed in the second working session. Both these projects took into consideration all three areas of pedestrian, bicycle, and pupil transportation safety. The panel was again asked to address the relevancy, necessity, and sufficiency of each project in achieving the overall program objectives.

Panel members generally supported the relevancy and necessity of the two projects proposed by TSP. The sufficiency of the projects' methods for accomplishing the stated objectives was, for the most part, considered appropriate.

A number of questions were, however, raised regarding method of the "Countermeasure Support and Implementation" project. Participants felt that the mechanics of obtaining support under that proposed project were too vaguely stated. NHTSA was urged to specify clearly how funds will be administered under that project before it is implemented.

A general concern was expressed about the lack of criteria for countermeasure implementation. Participants noted that there are no specified criteria for releasing or withdrawing a countermeasure. Better information about the effectiveness or ineffectiveness of countermeasures was viewed as being both useful and more economical from the state and local level perspective. The panel recommended that NHTSA establish specific criteria to determine at what point countermeasures are to be transferred to the states.

\subsection{Technology Transfer}

NHTSA's technology transfer efforts in the pedestrian, bicycle, and pupil transportation safety area are housed within TSP. The specific project proposed by TSP takes into account all three topic areas. The questions of relevancy, necessity, and sufficiency of the project in meeting safety goals were again considered by the workshop group.

Technology transfer efforts were viewed as extremely relevant and 
necessary by the workshop panel. Questions about sufficiency were, however, raised. Participants saw the activity as being disjointed rather than systematic. Two points were addressed:

- the ability to capture information, and

- the ability to make information available to potential users.

It was noted that much information is being produced under the sponsorship of state, local, and private funds. Workshop participants saw a need for NHTSA to include in its technology transfer function a mechanism for identifying and publicizing such work as well as that being done under NHTSA sponsorship. Participants questioned whether a NHTSA central office should be set up to identify, collect, and index information in a structured way and recommended the establishment of such a structured system.

The second aspect of the technology transfer problem was making information available once it was captured. This involves identifying the potential users, the users' needs, and a potential delivery system. Concern was expressed that information is not getting to the people who need it. The identification of potential users was seen as the essential first step in this process. It was felt that the current system misses many potential users, especially on the local level. These include groups not found within the traditional highway safety network (e.g., teachers) and not likely to be aware of the highway safety network and how it works. Workshop participants urged that better linkages to those local groups be established.

The need for a systematic and continuous system of delivery of information was emphasized. Participants noted while materials have been available upon being developed, they seem to disappear after the initial promotion. It was recommended that materials be placed in an information system for which they could be obtained later in time.

The panel strongly recommended that NHTSA establish a clearinghouse to gather and disseminate information on a routine basis. Panel members suggested this would make the technology transfer process more consistent and less fragmented. NHTSA was urged to examine existing systems in 
both the public and private sectors as models for the development of a NHTSA clearinghouse.

The workshop panel also suggested that NHTSA make use of existing networks to disseminate information. Among the strategies proposed were: working more closely with organizations such as PTAs or Kiwanis Clubs; publication of information in journals and magazines aimed at particular groups; greater use of library systems; and deliberate inclusion of educational material in established curricular units for grades $\mathrm{K}-12$. 

APPENDIX A

RESEARCH AND DEVELOPMENT

NATIONAL HIGHWAY TRAFFIC SAFETY ADMINISTRATION 



\section{APPENDIX A \\ RESEARCH AND DEVELOPMENT \\ NATIONAL HIGHWAY TRAFFIC SAFETY ADMINISTRATION}

This appendix contains the text of a slide presentation to workshop participants given by Dr. Alfred J. Farina at the Conference Opening. Dr. Farina is the Chief of the Pedestrian and Bicyclist Safety Research Branch of the Office of Driver and Pedestrian Research at the National Highway Traffic Safety Administration.

We are a branch of the Problem Behavior Research Division located within the Office of Driver and Pedestrian Research. The Office is one of five units that comprise Research and Development ( $R \& D$ ). Our counterpart on the operational side is the Office of Traffic Safety Programs.

As to the major purpose of the workshop-we will be asking you to focus on our future projects--both in $R \& D$ and those dealing with technology transfer on TSP's side. The total is approximately eleven projects. That is the scope of what we have ahead of us. However, this will require some knowledge about what NHTSA has done in the past. Otherwise, you are just looking at, as Kent Joscelyn aptly said, snapshots without relevant background. I want to provide you with some background information on the research portion of the program. Larry (Pavlinski) will do the same for the TSP projects. That should leave you primed for the discussion of the proposed projects.

First, let me speak of NHTSA's scope of responsibility in these three areas. We do not have total control over the efforts that belong in this area. It is important that you realize that. We share responsibility and safety efforts in these three areas with the Federal Highway Administration and the Consumer Product Safety Commission. Where appropriate, we have joined forces with these two agencies to accomplish mutual goals through projects. Basically, we try to create solutions, or 
countermeasures, to the accident problems. We use three approaches to do so, primarily because these are within our charter. We use training programs, traffic safety regulations, and public information and education. Parenthetically, I might say that we also do safety research on the vehicle itself, primarily to reduce injury severity. That is done by other elements within NHTSA. It is not within the province of this workshop.

I will begin with the background for pedestrian safety, since NHTSA got into that first and because it does set the pattern for the other areas. First, the magnitude of the problem that we have been addressing in pedestrian fatalities runs about seven to eight thousand fatalities a year. It constitutes about seventeen percent of the highway problem and, to that extent, it is the number two vehicle crash problem.

It (pedestrian accidents) is basically an urban problem. Eighty-five percent of the accidents are urban; sixty-six percent of the fatalities are urban. In no way should that slight the rural-suburban problem. If we look at our major cities, we find that, in many cases, forty to fifty percent of their highway-related fatalities are pedestrians. Here is a map showing cities over 250,000 that have at least thirty-two percent of their highway fatalities in pedestrian areas. Because of this particular distribution, NHTSA's initial focus in the pedestrian area was on the inner city.

This focus took the form of a study in which we tried to get at the causal elements of pedestrian accidents in the city. This 1969 study (listed as Project \#1 in Figure 2-1) added an important new feature to the conventional demographics approach being taken at that time. By conventional, I mean describing in detail to whom the accident occurred, where it occurred, time of day, month; cutting it into unidimensional slices in each case. We tried to add a new dimension and that was a concern for the behavioral errors on the part of the pedestrian, and the driver, that were contributing, directly and indirectly, to the accident itself. We were also interested in the contributions of the environment and the vehicle. With that now would you put on the viewgraph.

To facilitate this, look at the behavior, of the participants in the accident. A model of the accident scene was developed in this early study 
(see Figure A-1). It includes the processes or functions that one could hypothesize have to go on by the driver and the pedestrian. As he navigates in the road, search behavior, detection behavior, evaluation of what is received, making the decision to cross the street or not to cross the street are all involved. This then culminates in human action and vehicle action. I show you this because many of the questions that were asked in this initial study flowed from that particular model. It served as guidance to the interviewers as they interviewed the victims, the drivers, the witnesses, and examined the environment.

The information collected in this study was grouped into target-grouptype data, data about the victims and the other participants in the accident. Then, using the model, certain of the factors which contribute to the accident were termed "predisposing" factors. These factors did not directly contribute or key off the accident but were of a setup nature.

We will give you some examples of predisposing factors. Parked cars, for example, tend to screen the pedestrian from the driver and vice-versa. Alcohol is a predisposing factor in many cases. Age could be a predisposing factor. Other factors were more immediately related to the accident, i.e., they precipitate the accident. Examples include: poor search behavior, entry into the road without searching at all, and course selection, i.e., where does he choose to make his street entry? Having that information on the accidents, the researchers were able to sort them into types: piles which had common precipitating factors, common precipitating events, and common situation effects (see Figure A-2). I would like to say that an accident type is sort of a classical trap in the real world, into which people keep falling over, and over, and over.

The approach of taking the general class of pedestrian accidents and breaking them into specific types was productive. An analogy that can be used, but not pushed too far, is breaking down the category of general illness into specific diseases. The approach resulted in a large set of pedestrian accident types being generated. This slide shows a smaller subset of accident types that were found to make up a large part of the problem. Here, we have seven types that accounted for approximately fifty-seven percent of the urban accidents. They are represented on these 


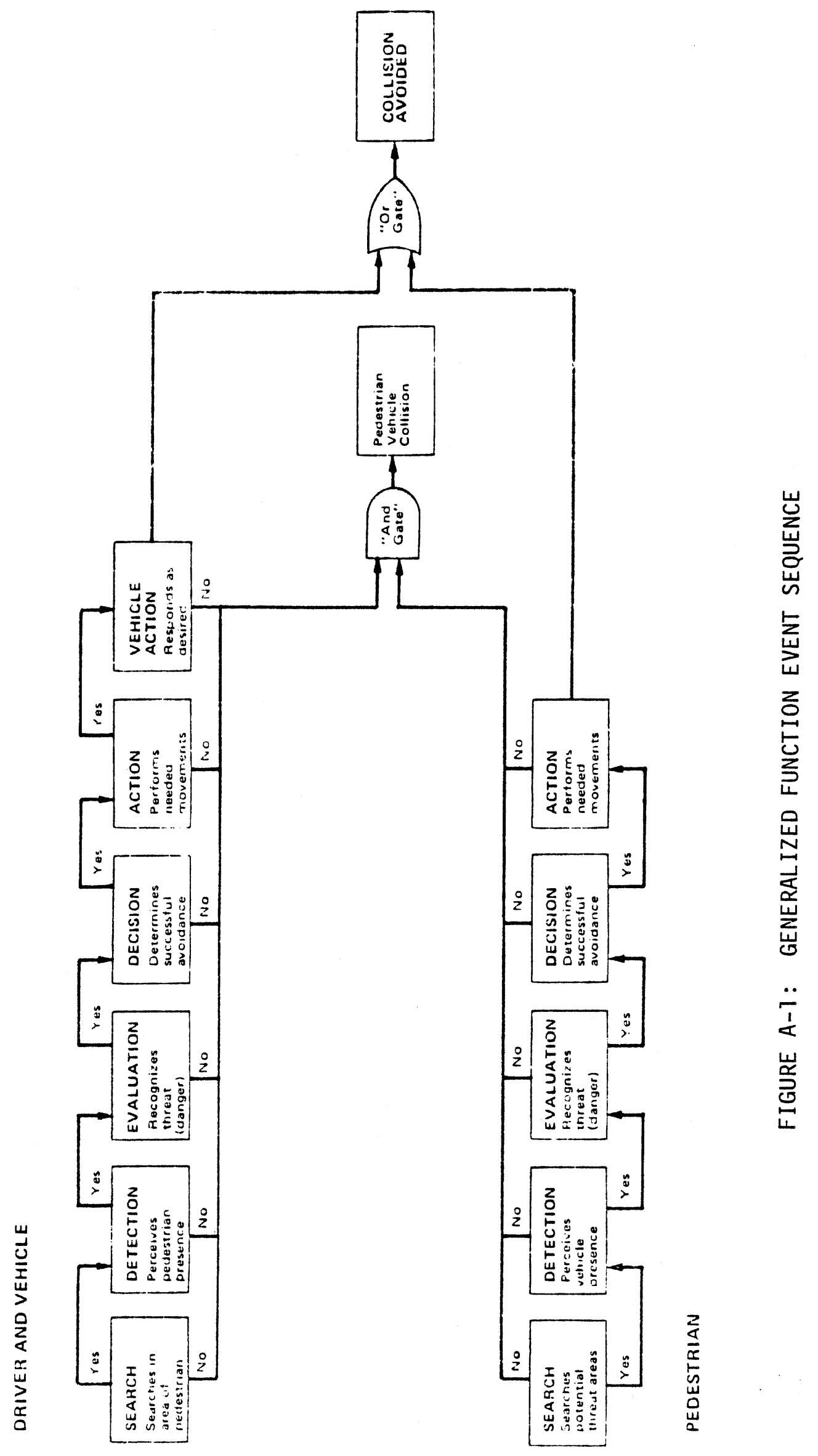




\section{ELEMENTS OF CAUSAL TYPE}

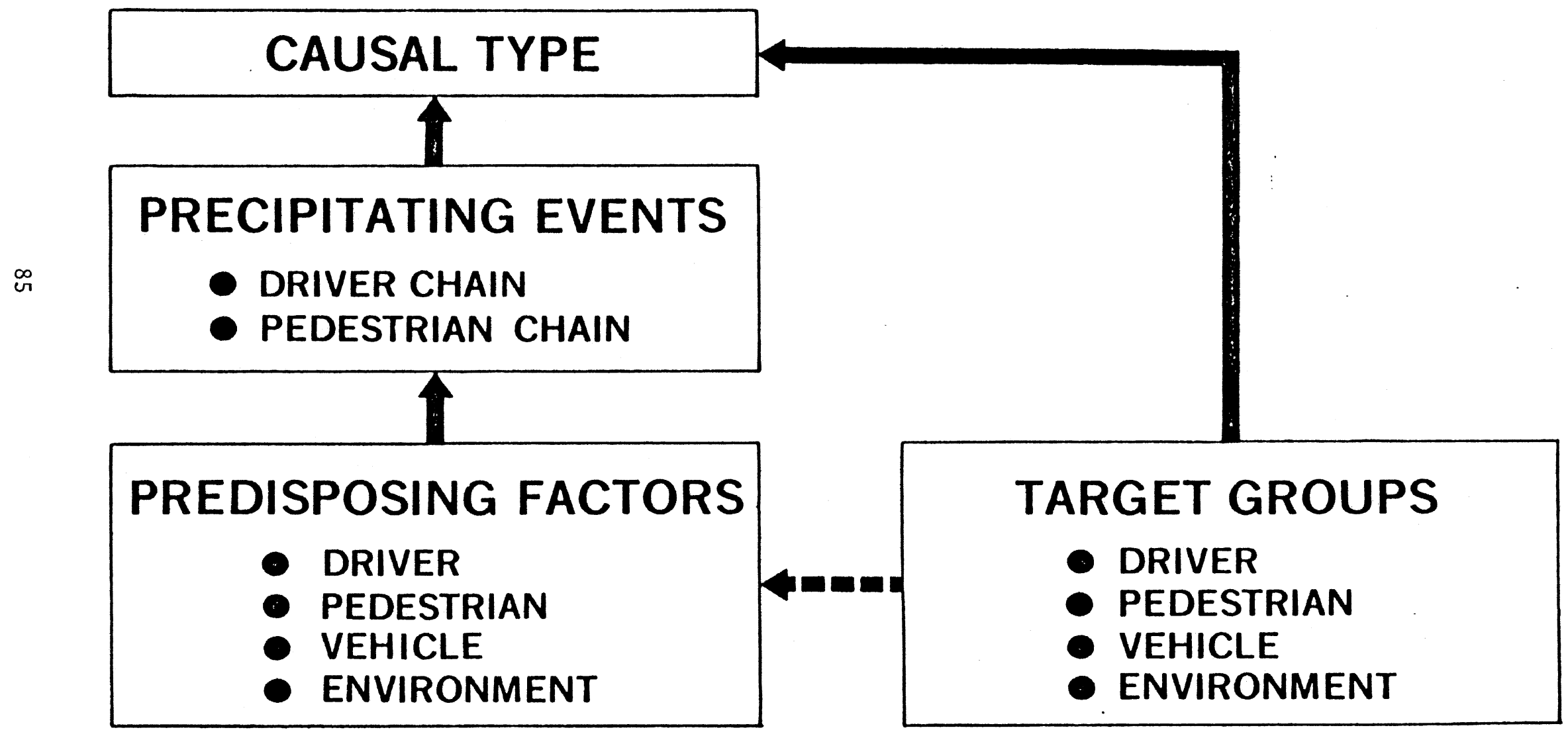


large posters scattered about the room, and you can scan them at your leisure (see Figures A-3, A-4, and A-5).

I do want to show you one type, with which you are probably already familiar and to show you how it flows from the original study done in 1969. The predisposing factors are the parked car, unattended children (we are talking about very young ones out on the streets), and unsupervised children, even if they are attended. The precipitating factors: lack of search, poor choice of location. This classifies as the dart-out first half, the technical name for it. There is a car moving along and the pedestrian is making the crossing. The presence of parked cars is not a necessity for this type. It can occur without that handicap. Just to bring it down to a little more realistic level, here is a shot that any driver would hate to see. Now if we want to see what it looks like in the real world, see a child engaged in it right there (photos not included in text).

Given that we had accident types, what did we do with them. The answer to that is that we develop countermeasures for them. As I indicated earlier, our countermeasures are in the areas of training programs, traffic safety regulations, PI\&E programs, operational procedures, and environmental changes.

Operational procedures would be guidance, let us say, to the police, using powers that they already have. Environmental changes, though beyond the province of NHTSA itself, are done in conjunction with the Federal Highway Administration. One feature of this approach is that you have multiple countermeasures against any one accident type. We found this to be necessary, because one kind of countermeasure does not do the full job usually. And secondly, they may not perfectly overlap, so you are picking up different segments of the target group. Also, they have different costs associated with them, and you may want to provide the locale with the choice of countermeasures based on their own financial constraints or any other constraints and resources.

Countermeasure development. The advantage of the approach I have described when it comes to countermeasure development is that we have 


\section{ANALYZE GENERAL PEDESTRIAN ACCIDENTS INTO SPECIFIC TYPES}

GENERAL ACCIDENTS

\section{SPECIFIC TYPES}
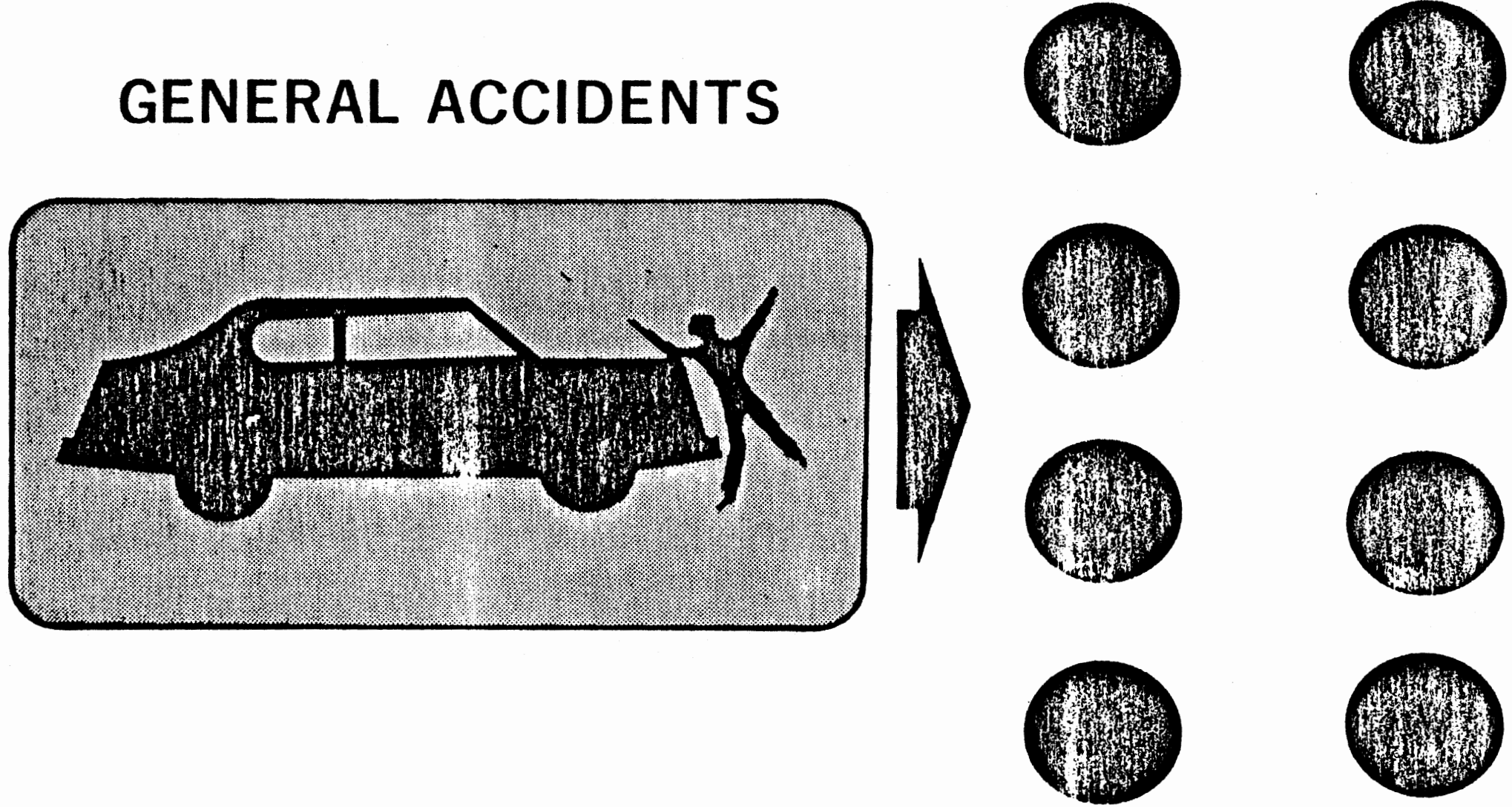


\section{INITIAL FOCUS: 7 TYPES COVERING 57\% OF URBAN ACCIDENTS}

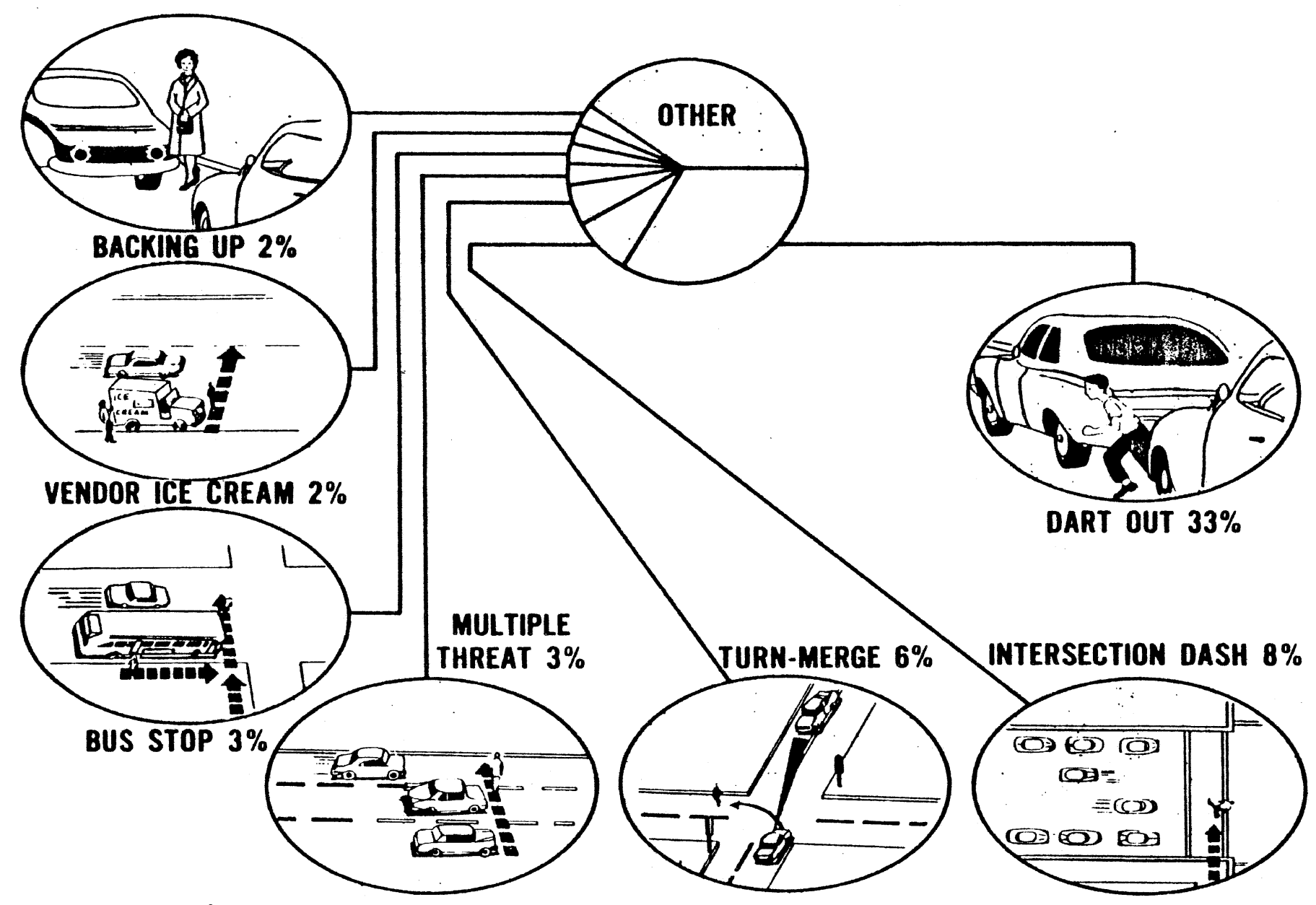




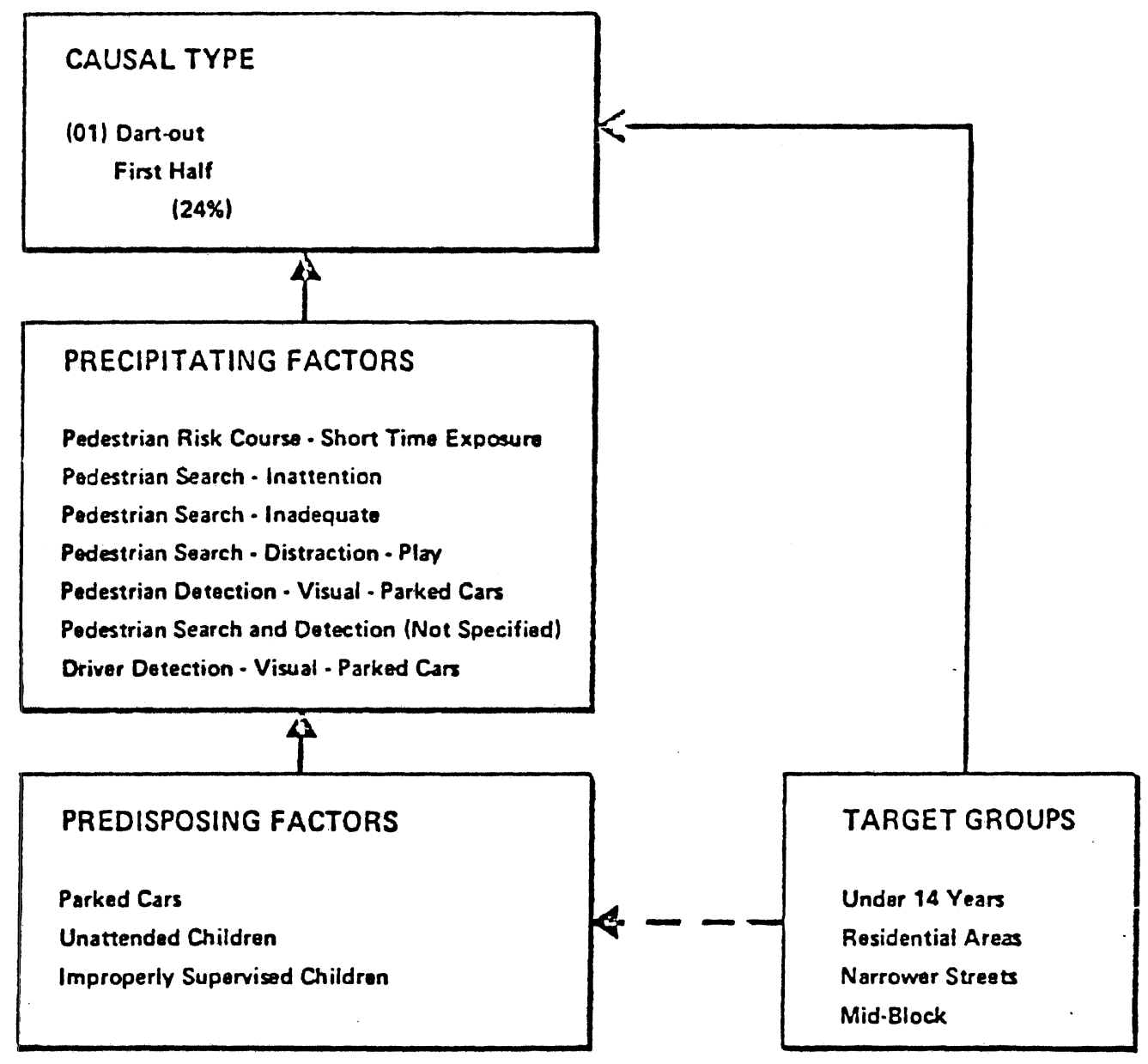

FIGURE A-5 CAUSAL PATTERN-DART-OUT

FIRST HALF 
more specific knowledge of the accidents, and, consequently, we can try and develop a very specific countermeasure. We are not dealing in the realm of the general as much as we are the specific. We can address the particular situation, and try to come up with a corrective behavior for it.

Secondly, if you are evaluating how effective you are, you can be more specific here, too. You can focus, not on general decreases in accidents, but did you reduce the one type you aimed at, such as the dart-out, or any other particular types that you were addressing.

Countermeasure development is a creative process. It is never a sure thing. We are seeking something in the countermeasure search that will break up that behavioral error sequence, the one leading to the accident. And that something could have its beneficial effect in one of several ways. For example, by helping to eliminate the behavioral error. In other words, a training program that trains the child in proper search behavior, thus eliminating the error. Or, it can nullify the effects of that behavioral error. To give you an example, the child still darts out, but in the ice cream vendor situation, we have an ordinance which acts on the driver, and requires him to come to a complete stop prior to passing the vending truck. So in this case, we are nullifying the effects of the child's behavior. The third way is to change the situation, so that that type of behavior is not required. An example there would be changing the bus stop location from the near side to the far side of the intersection, thus reducing the need to cross in front of the bus and getting away from that screening up there.

We have a research cycle operating from problem identification through countermeasure testing. I would like to give you a peek at that because you are going to be dealing with it when you deal with the projects (see Figure A-6). The research cycle begins with problem identification; for example, the 1969 urban study. It yields accident types. Then, given those accident types, we focus on certain of them, and we attempt to develop countermeasures. We test out their feasibility. In other words, did they change the subject's knowledge of the situation or did they change his/her erroneous behavior. If the countermeasure survives this test, which can be done in a one-year or two-year period, we then take it forward to 


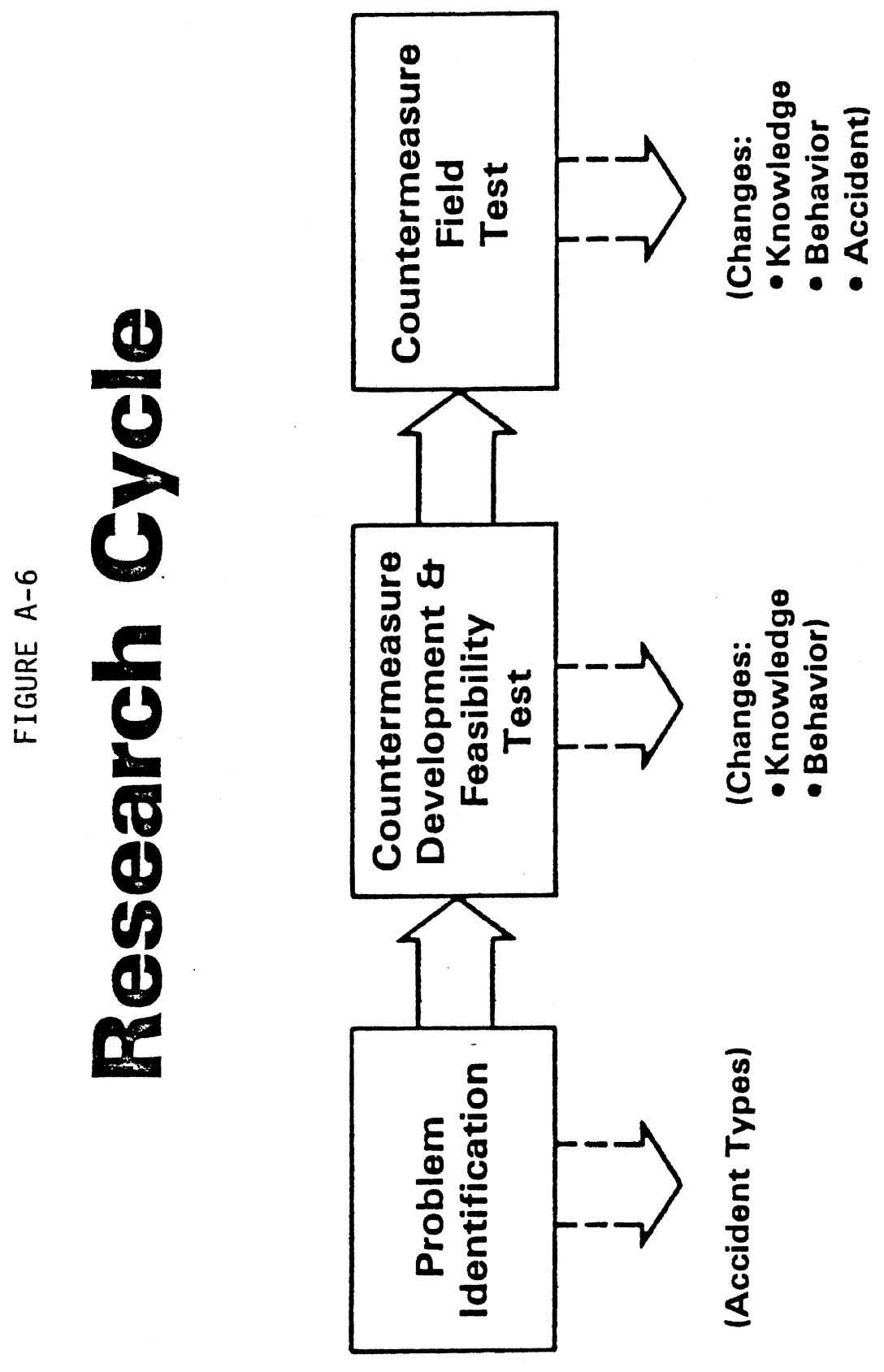


a field test. This is a larger-scale effort and a longer effort. What we are trying to do here is go that one step beyond and see if we have a bottom-line effect. Can we reduce accidents?

To see how this approach has been applied to the research over the years, I am going to direct you to that edition of the "Sunday Times" that is tucked away in your brief cases. Could we have the lights for a moment. Thanks. What I am talking about is the flowchart that is in your pack (see Figure 2-1 in Chapter Two). What you have there represents the total past and future programs, from 1969 forward to 1985 with both our data and that of TSP. Projects with broken lines, out toward your right, are future projects. Those are the ones that we will be discussing over the next two days. I would just like to point out a few trends in the process I was talking about, the research cycle. This, for example, is the ORI study, that 1969 study yielding urban accident types. Then following one particular type, the dart-out accident, with safety messages, testing their feasibility; then the longer-term testing out in the real world for accident reduction. Similarly, this study, feasibility test of the training program, went ahead to a field test. Or, in the case of traffic regulations for nine of these accident types, the regulations were devised here. Then we begin to test them out in individual projects. The ice cream vendor study, for example, begins here with identification of the vendor accident type. We developed a regulation for it. We then went on to testing it-field test-and that is the one that yielded the seventy-seven percent accident reduction. The projects we will be discussing are out here in the 1982 to 1984 range. I have thrown in FY85 just to indicate the length of some of these that were started. We tend not to do isolated projects; they are connected. There are also special studies, special one-time projects in which we will look at measurement procedures or attempt to develop a data base so that we can continue our research in the cities themselves.

What is this approach producing? Is it working? The R\&D approach has yielded three kinds of products: the accident types, countermeasures, and procedures. I want to cite the procedures because the procedures attempt to wrap it all up in one ball so that it has greater utility for 
people who want to use them. In terms of accident types, we have done the problem identification work in the areas of urban pedestrian, rural pedestrian. We have done problem identification in the area of bicyclemotor vehicle accidents. And we picked up information on the pupil transportation-pedestrian problem within the rural studies on pedestrians. So we have fairly well gotten a handle on what it is out there that is causing various problems in the areas of interest.

In terms of countermeasures, we have some that have emerged from or are emerging from the pipeline; for example, pedestrian safety messages aimed at the dart-out accident. The Willy Whistle messages have achieved twenty percent reductions in our field tests. Willy is a character with a whistle. He appeals to children well beyond our fondest dreams. Adults seem to like him too. You will be able to see the actual films that he acted in and the messages he is giving out.

We have training programs. We have some of these materials in the back of the room. These were tested in Toledo and New Orleans, and one program accounts for over a twenty percent reduction in accidents. We also have traffic safety regulations. The model ice cream truck ordinance is our prime example at the present time.

These are the countermeasures that are emerging first out of the research pipeline. We have a countermeasure availability chart (that can be seen more closely in this working session). What you see here are about twenty or twenty-one countermeasures that we are working on and the expected time at which they will be available for technology transfer. As with all research, there is the caveat that the research may not be productive. Some of them may bomb and never reach the technology transfer stage.

How does all this get infused into a local network-states and cities? 
Our intent is that the local pedestrian accidents would be analyzed at the local level. Given that you now know what your problem is, you will have countermeasures specific to the various accident types, and you apply them as desired to your problem (see Figure A-7). The problem with this approach is that accidents do not come labeled in the real world as "dartouts," "multiple-threats," etc. So we develop procedures that would enable people at the local level to go ahead and type their own pedestrian accidents. This is a training program that teaches people to code their pedestrian accident types. What you are trying to do is to come up with a profile of your own accident picture in terms of the accident types. When you are dealing, for example, with a city that has maybe three thousand accidents a year, the efficiency afforded by the computerized version of the accident-typing program is desirable. Further, in an attempt to bring together the major products of what this approach has produced--those being the accident types, typing procedures, and the countermeasures themselves--we put together the Pedestrian Accident Reduction Manual. It describes the accident types and how they were developed. It tells people information on acquiring these typing procedures, the training programs. And it has the countermeasures illustrated in a "catalog" fashion. They give you information with regard to the countermeasures, much like a Sears catalog. It does not tell you all the information about the countermeasure, but enough for you to see if you are interested. Does it fit your resources? Would you want to follow it up and acquire it? Realize that we are talking, in some cases, of training packages, films, etc. I want to hold off on going into these implementation procedures any further since the technology transfer section on your agenda focuses on this.

In summary, the research illustrated in the flowchart focused on actual problems as identified by research. It embodies a range of countermeasure approaches and solutions. It attempts to test the countermeasure effectiveness in terms of accident reduction, where feasible and possible. It is, we believe, receptive to the needs of the state and local users. A good deal of the reason that many of you are here today is that you are practitioners and we would like to increase the utility of our products. 


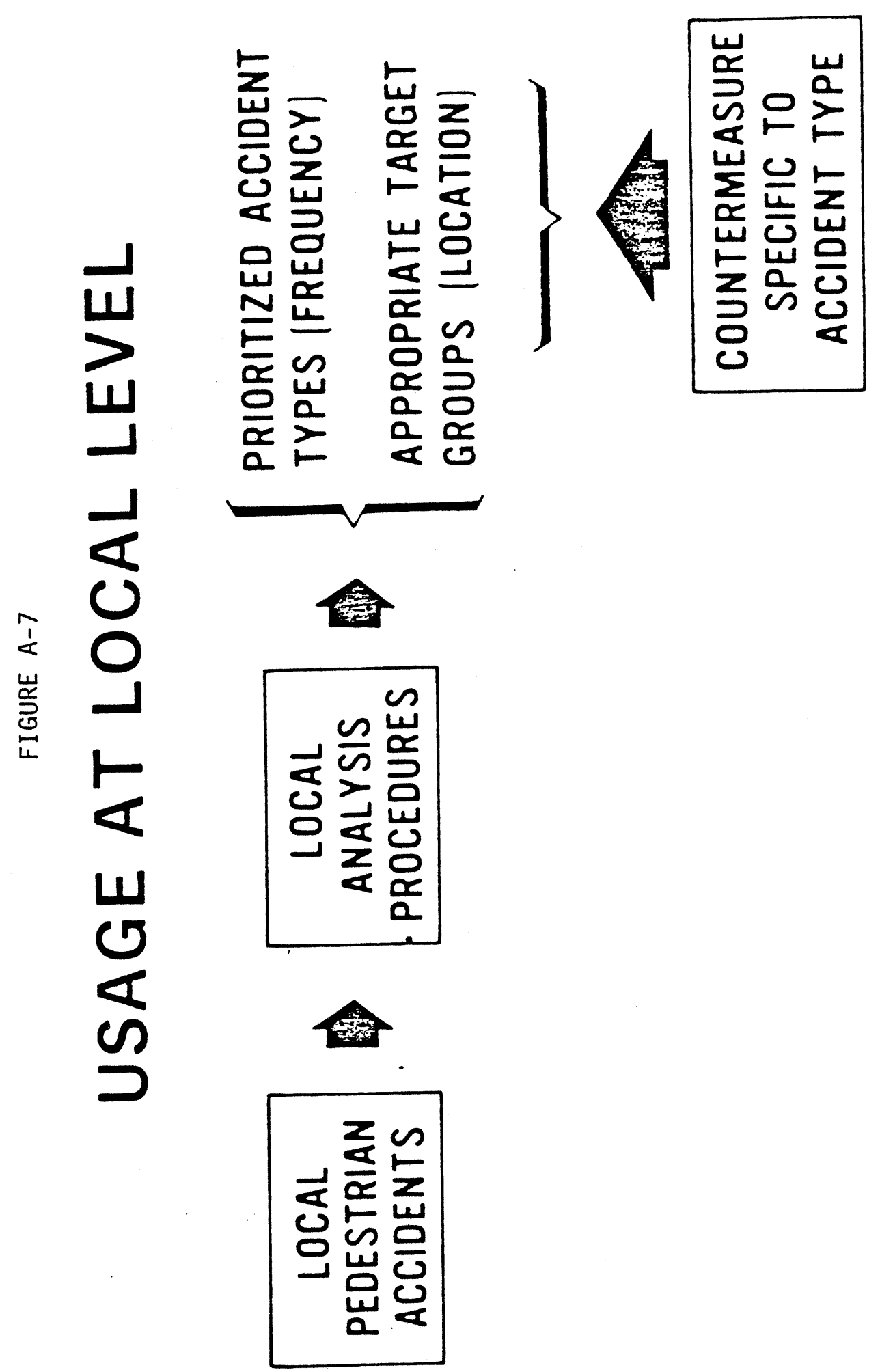


Having covered our research approach, within the context of the pedestrian area, I would like to move more quickly in discussing the background of the bicyclist and pupil transportation.

We began our research efforts in the bike accident area in 1974 with a problem-identification study. It is noted on the flowchart; it is project number 11 . It focused on rural/urban/suburban bike riders and investigated only bike-motor vehicle accidents, and not the much larger set of bicyclist (only) accidents. Those are currently not within NHTSA's purview. The study was patterned on the basic pedestrian study, in that it used a model of the accident process to come up with the questions that were asked. It focused on behavior and generated accident types. In fact, there were about thirty-six such types. Again, whenever you have a large number of types, a small subset appears to account for the majority of accidents. Some types get very, very tiny. We broke them down at that level for purity's sake, knowing we could always regroup later. Beginning at age four, both fatal accidents and nonfatal accidents rise steadily to about age twelve, are level through age fifteen and decline dramatically thereafter. So we are seeing a young rider. The types of accidents that the study generated totaled thirty-six, which fell into about seven classes. I would like to show you one primary type: the ride-out type. The bicyclist enters the roadway from a driveway, alley, over the curb, or shoulder without slowing, stopping, or searching for oncoming traffic. It is almost like a dart-out. We also have wrong-way riding here (a large contributor to this particular type). Mainly, the bicyclist is not expected from that direction, from the drivers' view of the world.

The next step in the bike area is to develop countermeasures for these accident types. The study that we sponsored covered all the types and all the countermeasure approaches. We were trying to get a jump on the bike area instead of doing a single study on a single accident type. The study is still ongoing, and it has produced prototype countermeasures, totaling about ten safety messages addressing a variety of types; nine traffic safety regulations; and four training programs. Future research then will select from among this wealth of riches and field test these countermeasures. As with the pedestrian area, we are devising a way for the localities to 
type their bicycle accidents.

This brings us to the pupil transportation area. It is a new $R \& D$ area, recently added to pedestrians and bikes, and covers a multitude of research areas in itself: for example, driver education, vehicle design, lighting system, and pedestrian seating. The largest part of the fatalities problem associated with school buses is the pedestrian problem. That was the rationale for assigning it to the pedestrian and bicyclist area. We, as I said, were pursuing the school-bus-related, pedestrian accident prior to receiving the entire area itself. In the rural pedestrian study, we identified the accident. We have developed a bus training program. In the regulations area, we have come up with a school bus regulation that attempts to consolidate many of the good points that are scattered at the present time. We have some ongoing research in the pupil transportation area, and we are seeking to enlarge our accident base. It is very small. We have about forty-six cases at the present time, done in in-depth fashion, that are providing our basic information.

You see that a wide range of research topics are considered in this area, for example, the vehicle, driver education, etc. These topics may require the expertise of $R \& D$ researchers outside the particular branch or even division in which we are lodged. In the project discussions, some of those people will be present so they can provide input to those projects that reflect their area. 
APPENDIX B

TRAFFIC SAFETY PROGRAMS

NATIONAL HIGHWAY TRAFFIC SAFETY ADMINISTRATION 



\section{APPENDIX B}

\section{TRAFFIC SAFETY PROGRAMS \\ NATIONAL HIGHWAY TRAFFIC SAFETY ADMINISTRATION}

This appendix contains the narrative for a slide presentation to workshop participants given by Mr. Lawrence Pavlinski at the Conference Opening. Mr. Pavlinski is a member of the Office of Traffic Safety Programs at the National Highway Traffic Safety Administration.

I want you to take a quick look with me at what we are calling Traffic Safety Program (TSP) objectives. Every time you see the word pedestrian, read pedestrian, cyclist, and pupil transportation. You can read seventeen or eighteen programs into these objectives if you like. We are trying to work with state and local communities to get the kind of research you are looking at, and the products related to it, out to the users in the best fashion. We are going to be talking about how to improve that system with you as we go along. We also are concerned about the difficulty in finding a person responsible for a program when we go to a state or community. We are concerned about the uniformity of state laws, as well as records and data. As we walk through some of these projects, you will hear people saying we really do not know enough about that. So focus on some of the things we are doing or on records and data needs. Those of you who are researchers know the difficulty you have had in accessing information; some of you had to go out and interview participants to find out more information. Our basic situation is to take the information and agree that this new type of information will assist the community in actually reducing accidents. We think it is very effective.

I would like to run through quickly the pedestrian activities that were going on while research was being accomplished. We said, "Hey, we can't 
just sit around and ring our hands while these guys are coming up with research information." The Highway Safety Act of 1966 included the word pedestrian, and the Secretary of Transportation shall have a standard on pedestrian safety. So we made our "best professional judgment" on that and came up with a document called Pedestrian Safety. It is one of eighteen Highway Safety Standards. In conjunction with people in the Federal Highway Administration, we produced the Pedestrian Safety Standard (14) some ten or eleven years ago.

We talked about alcohol content in the body. We just finished a research project in New Orleans where we analyzed the alcohol level in not only the injured pedestrians but also the fatal. For years you have heard about the fatals being tested. So the uniqueness of that one is the testing of both fatals and the injured pedestrian.

Best professional judgment talked about land use planning: we have to injury- and safe-proof the school areas. At the same time, we use words like behavior characteristics; we use words like accident-avoidance techniques. Driver education courses should have this information in them. Driver improvement courses and driver license examinations should have pedestrian information. I suspect that if you go to your states and communities, you still have to search to find questions on exams and in the courses related to pedestrian, bicyclists, and pupil transportation. I take that as a personal challenge each time I look for programs for children, youth, and adults. So we are talking about a lot of things now with research that we talked about then with "best professional judgment."

Back when Congress said, "Take a look at the pedestrian and the bicycle situation and tell us about it," we put that in a congressional report. One of the things that came out of that was the traffic laws commentary that the National Committee on Uniform Traffic Laws and Ordinances did for us. The interesting thing is that we talked about the need for interstate uniformity, the need for some reasonably uniform vehicle code. Those needs generally exist today. We have not searched to see what improvements have been made. We produced the report to Congress and called it the Section 214 study. It goes into things about 
alcohol, policies, and records. We find that we said here, "No national legislation required-nothing from the federal government." It is a state and local activity. I sincerely believe that. I said that for twenty some years. We all live in cities and communities. It is all of us in some city and state working on that. That is what this thing says. So I ask you to look seriously at some of the things in these projects.

We then said to the world, "There's something new coming out of research." We produced a little pamphlet and called it the blue book. We said, "There's a new approach to this, really."

We said, "Now we've got to take it one step further and we'll provide this to the regional offices and the governors' representatives.". So each state has a copy of the presentation you are going to see in about five minutes. The point being that we then said to the world again, "Here's another way to look at pedestrian accident types, and here's some countermeasure approaches, but it involves policy changes. It involves records and data changes. It involves a new creative way of looking at the situation." We went one step further in 1976 and produced a program memorandum. Again we said, "Here's a national perspective," after we told about this pedestrian accident thing. You start with laws, you start with the person in charge of the program. You start examining from the engineering viewpoint. We put in terms like mobility capability for elderly and handicapped. We had not used those terms before. We are just getting into that kind of research now. So we are a little bit ahead of the game in talking about it. We have some pamphlets up here for you.

The thing we told the world about was the Model Ice Cream Truck Ordinance. With one radio and $\mathrm{TV}$ spot in Detroit, the researchers reduced the accidents seventy-seven percent. We are also excited because the speed reduction past the ice cream vendor situation was as good or better than a stop sign. They are extremely excited about that. So there was a kind of synergistic thing that occurred out there. I will tell you a little bit more about that one.

We took our concepts and ideas from research to the Sixth Traffic Records Forum down in Dallas last summer. We said, "If you take another 
look at your data, this is the kind of thing that you might be able to find." We are working up what we call a Pedestrian Accident Reduction Guide. It is going to be an assist for state and local people in taking a look at the accident types and at countermeasure information. We presented some information to the traffic engineers at the ASHTO (Association of State Highway and Transportation Officials) meeting. We also are suggesting that the Highway Safety Committee of ASHTO, which meets out in Las Vegas next month, have a discussion for a few minutes to whet the appetite of the state traffic engineers about these needs.

Al did not get into it in detail, but we have accident types on freeways. If you are from Missouri you know that the interstate system has a particular pedestrian-accident problem in Missouri, and you should be concerned about this.

Activity in the documentation of manual accident typing and computer accident typing is almost finished from a research project.

We imposed on our researchers once before to assist some communities. We did the job for, and with, the local people. We will talk a little bit about the technology transfer project as we move into the activity.

I just want to show you the pedestrian audio-visual at this point and we will come back to the pedalcyclist review and the pupil transportation area.

This is a seventeen minute presentation. It is out there in the regional offices and the Governor's Representative's offices. It is available. It is for people who are looking for a way to start a pedestrian program. We recommend this as a starting point. So please take a look at this with that attitude.

(Presentation given at this point)

We would like to recognize that Frank Kennel is here from AAA. Frank picked up on the idea of the stop at the curb, look left, right, and left again. He had the five pamphlets in the preschool program that they produced showing a dad on his knees, at the edge of the curb, teaching the child how to do this. It is a message for parents. The pamphlets are available. There are a lot of good ideas and information out there that 
we are starting to exchange. We believe this message is one of the keys to this thing. I think you ought to take a look at some of it.

The pedalcyclist term is used intentionally. We have been using it for several years. I think you should realize that the ANSI standard-I think all of you know American National Standards Institute-uses it. The Traffic Records Committee used it out of NSC (National Safety Council). We think it is a proper way to go. Those of you who look at your state laws realize a unicycle is not a bicycle, an adult tricycle is not a bicycle, and a quadricycle is not necessarily a bicycle. The pedalcyclist term covers a family of terms that include all these other cycles. Sometimes they are not even vehicles in your state. While our research is two-wheel and bicycle-motor vehicle, be concerned and aware that the program and problems exist across the board.

You should be aware that there is no NHTSA standard on pedalcyclist safety. We talked about it for about a ye: " and a half in 74, 75, and 76. We actually developed the draft standard in conjunction with and in cooperation with the states and local people. We talked with a lot of people and we think we could go on the street with it. But there is no pedacyclist highway safety standard from our office. There is a Consumer Product Safety Standard, the product being the bicycle. There are 119 hospitals around this country that participate with the Consumer Product Safety Commission on the National Electronic Injury Surveillence System (NEISS). Everyday, the emergency rooms input to the computer the kind of trauma and the product associated with accidents. There are a lot under- and nonreported. I think you will hear that kind of discussion about the need for data.

Federal Highways does the planning, designing, and constructing of the bikeways. We are concerned with the safety aspect of it. We will tell you while the research was going, we took another look at the bike side of this thing in conjunction with the other study we told you about. The police group talked to the law enforcement group. The laws people looked at ped-bike laws, and the same kind of parallel was there. I think again we ought to be concerned that there might be some alcohol-related 
violations with bicycles and mopeds that we are not aware of because we are not asking for chemical tests of those people involved in violations or crashes. Do you recall reading the headlines about New York? We had three cyclists kill three pedestrians. There is something to look at, and they are not little situations.

From there, we looked at Bike Ed 77. We brought in about 250 people. We co-sponsored, with the Consumer Product Safety Commission, a National Conference, and talked about what is it that is out there and what are some of the needs. One of the needs was to do this (the National Conference) on a regional basis because we need the information and the activity at the state and local level. So we convened ten regional workshops on bicycle safety education.

We have a coterie and constituency of interests out there. The people are in the back yards where you live and work. There are about 450 people out there. There is also the League of American Wheel Men, certifying instructors with Forester's program. Forester developed that as a one-semester course at the junior college. The point is that there are people doing it. We did cooperate and participate with the Federal Highway Administration and Northwestern University in the one-week workshop on urban considerations related to pedestrian-bicycle. I think it is getting a lot of demand, and I am pleased to see it.

Travellers Insurance took the Ken Cross research, which Al showed you, and made a film called "It's Your Move." It is on the free loan basis. We think there is a lot of technology from research that not only is coming out of our office, but from other people. The AAA Foundation hired Ken Cross, our researcher, to produce a packet called Bicyle Safety Facts and Issues, which is going hot fire out there. People are using the packet information. It covers a lot more than we said in some of the other workshops.

So there is a lot that the private sector and the other interest groups are doing. Dan Burden was part of the Missoula, Montana program-a 402 project. It was a matching grant program. The uniqueness of it was that 600 fourth-graders took not only the research concepts but went on the 
bike, in addition to the classroom. A kind of nice breakthrough. It is going to go city-wide up there this year and maybe state-wide, I hope. The only thing I am trying to encourage them to do is buy the helmets as part of the safety project, because if we believe what the emergency room data says-falling off, loss of control, upper torso, head injuries-then we have got to teach them how to fall off safely. We do it for horses and out of airplanes and off gym equipment in the classrooms. But we cannot get them to buy $\$ 38.00$ helmets, necessarily. As part of the project, I think we could put that in as a safety item. Katie (Moran) was fortunate to be out in Denver, and with the Gates Rubber Foundation, she participated in developing a course for the Denver school system. You will hear a little bit about that. Again using the research that your tax dollar and mine paid for, we have come a long way with some of these kinds of programs.

We are not the only outlet for technology transfer. I think there are a lot of people with a lot of interest and organizations with a lot of capability that are doing it.

Even though there has been relatively little research in pupil transportation, I want you to know that Dave Soule has been quite busy. While we do not have much research, you are going to hear about the threshold being opened up on pupil transportation. We have a lot on the vehicle, on the Federal Motor Vehicle Safety side. There are some twenty-eight standards related to that vehicle. It is an ongoing process. We took the side that says-but the vehicle gets on the road, what about the driver; what about the color of it; what kind of lighting system; things and routes? While we do not have any research on the operational aspect, here is our best professional judgment. So we did in fact put out Standard 17. But while we were getting ready for that, we again asked the National Committee on Uniform Traffic Laws and Ordinances to take a look at what happens out there. If you look at your school buses, those of you who live in Maryland and Virginia know that you have red signals only; those of you in Pennsylvania know that you have yellow and red signals on the bus; and in the West you probably see stop signs that swing out from 
the side. Maybe you see two stop signs. You may have continguous areas, where a person from Michigan drives into Indiana, you will find that the law changes and the stopping law changes and the red signals are activated prior to the stop. The layman following the bus or advancing to it from the front really does not know what the stopping point is. We say the reds should be activated at the stopping point for loading and unloading only; the yellows are advance warning. We have a lot to do in those kinds of operational activities. Dave was very active in the program related to the development of Highway Safety Standard 17 based on professional judgment. A lot of data is still needed.

We then came up with school-bus-instructor training. We had a coterie of people trained. Those people are out in the states now, and we are really not sure where they are. Do they participate? Do they stay in the program? Some will be promoted out; some get transferred out; some choose to work in other program areas. So while we have done that part, we are not sure that it is still ongoing.

We had a school vehicle safety report to Congress, and again while it was primarily intended for the vehicle side, there is a lot in here about the fact that pedestrians are involved heavily. We still need a lot of data, a lot of investigation, a lot of research, and a lot of study activities. We also completed one related to exemplary programs. If you take a quick scan of it, you will find that we talked about driver training, field trips (one great unexplored area), special education, handicapped transportation, maintenance, recordkeeping, safety techniques, and administration.

There are a host of things related to the operational capability. Dave is working on a parallel to the pedestrian program, "An Acceptable Level." Seventeen minutes of a hot shot presentation that is just about ready to be packaged. You will be seeing that soon out in the field, again, used by the regions and the states. We think that is the way to look at it. 
APPENDIX C

PEDESTRIAN ACCIDENT INFORMATION 



\section{School Bus Related Pedestrian Fatalities (FARS-1978)}

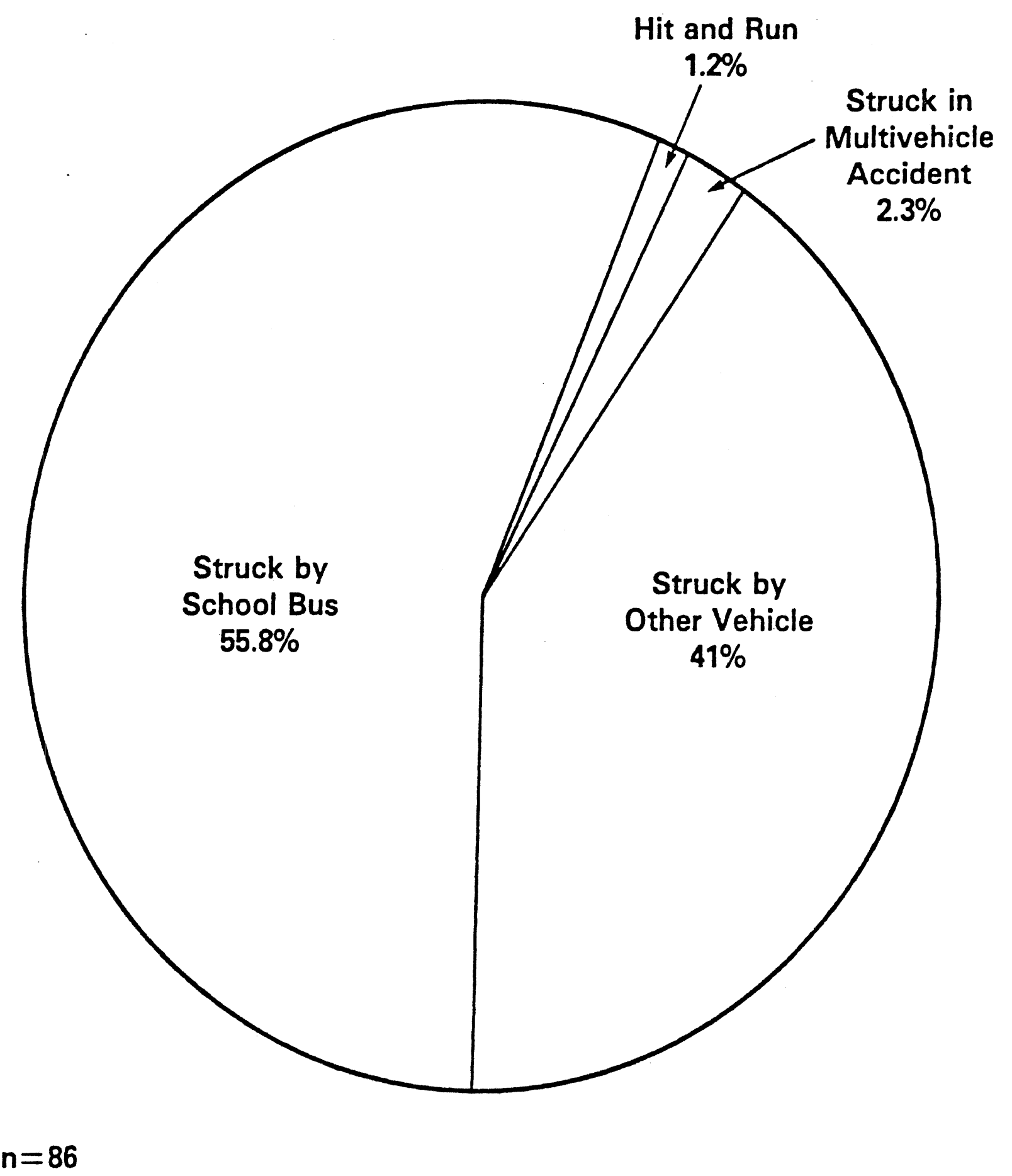




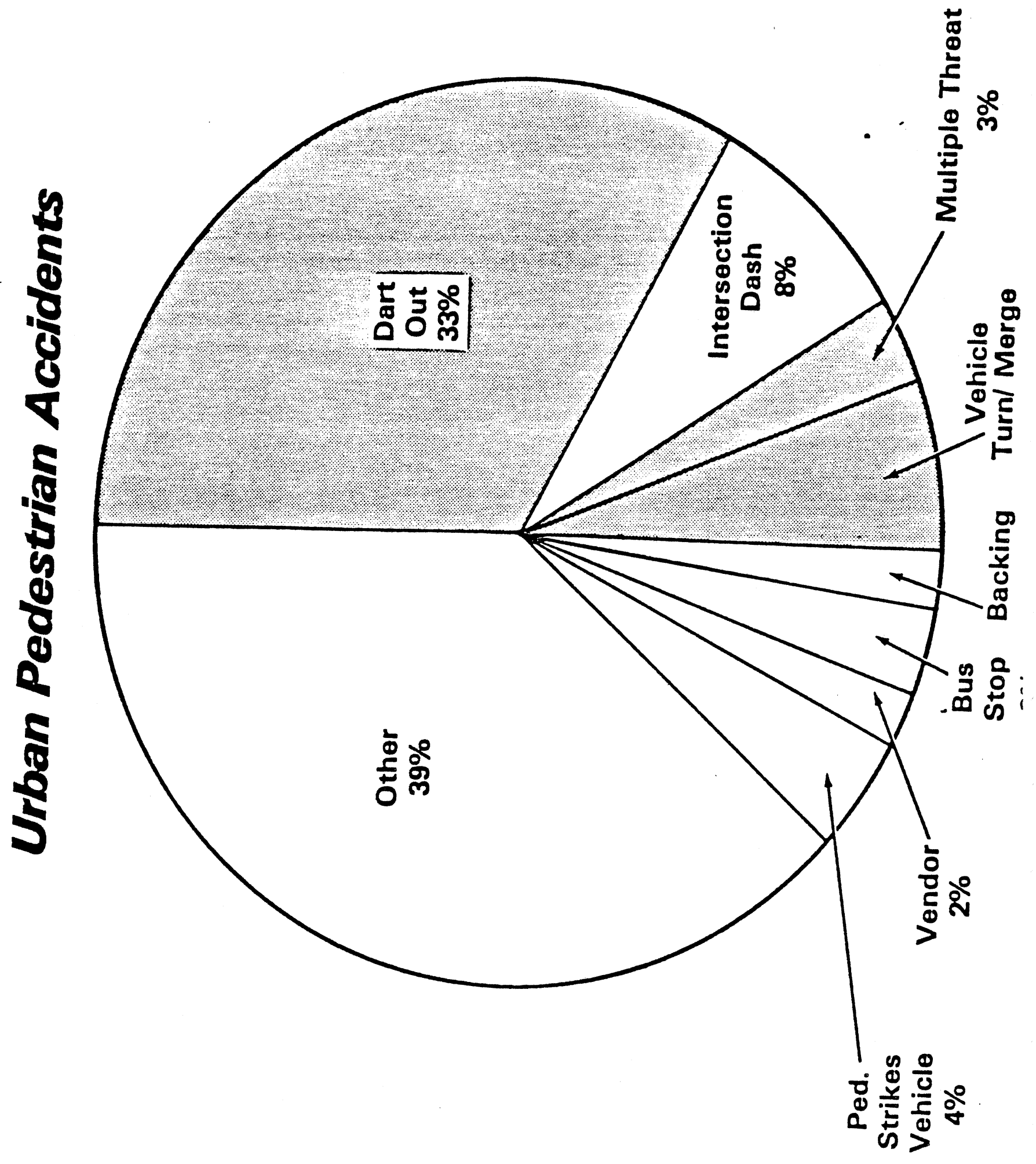




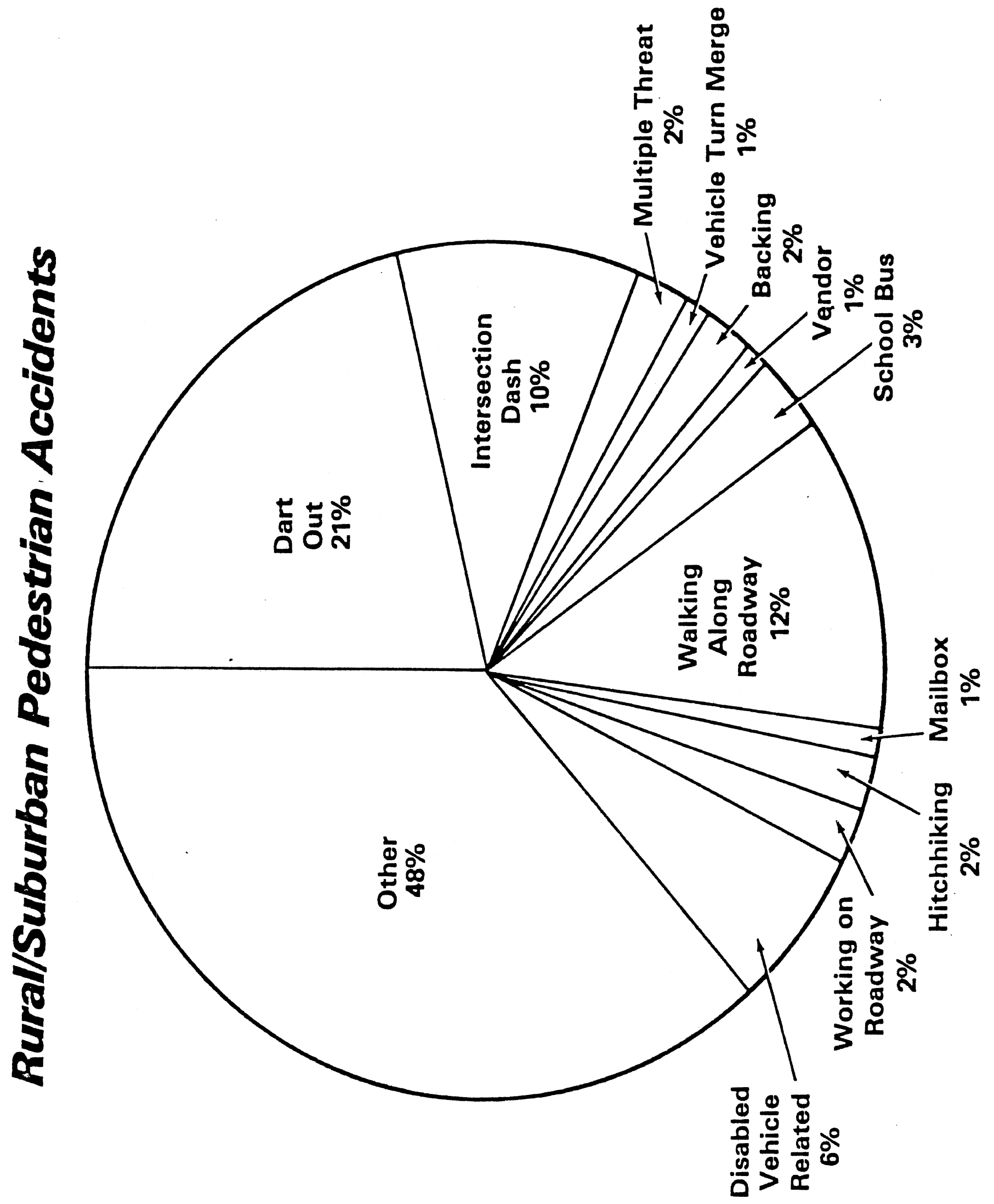




\section{•}


APPENDIX D

LIST OF WORKSHOP PARTICIPANTS 


\title{
APPENDIX D \\ PEDESTRIAN, BICYCLE, AND PUPIL TRANSPORTATION \\ SAFETY WORKSHOP
}

This workshop was held on 27-28 October 1980. The following persons participated; their titles, positions, and addresses are those at the time of the workshop.

\author{
Pamela T. Anikeeff, Ph.D. NRD-42 \\ Contract Technical Manager \\ U.S. Department of Transportation \\ National Highway Traffic Safety Admin. \\ Nassif Building \\ 400 Seventh Street, S.W. \\ Washington, D.C. 20590 \\ Robert Barlett \\ National Transportation Safety Board \\ 800 Independent Avenue, S.W. \\ Washington, D.C. \\ Frank Bennett \\ California State Department of Education \\ 721 Capitol Mall \\ Sacramento, California 95814 \\ Richard D. Blomberg \\ Dunlap and Associates, Inc. \\ One Parkland Drive \\ Darien, Connecticut 06820 \\ Thomas Brahms \\ ITE \\ 525 School Street, S.W. \\ Suite 410 \\ Washington, D.C. 20024 \\ Jennie Brown \\ Department of Public Safety \\ 207 Transportation Building \\ St. Paul, Minnesota 55101
}


Daniel Burden

State Bicycle Coordinator

Florida Department of Transportation

605 Suwannee

Tallahassee, Florida 32301

Joseph Cameron

U.S. Department of Transportation

National Highway Traffic Safety Admin.

Nassif Building

400 Seventh Street, S.W.

Washington, D.C. 20590

Michael Cosgrove, Ph.D.

Technical Manager

Applied Management Sciences

962 Wayne Avenue, Suite 701

Silver Spring, Maryland 20910

Maureen Craig

Office of the Secretary of Transportation

400 Seventh Street, S.W.

Washington, D.C. 20590

Dan Daniels

U.S. Department of Transportation

National Highway Traffic Safety Admin.

Nassif Building

400 Seventh Street, S.W.

Washington, D.C. 20590

Richard Dueker

Applied Science Associates

Box 158

Valencia, Pennsylvania 16059

Leroy Dunn, Ph.D.

U.S. Department of Transportation

National Highway Traffic Safety Admin.

Nassif Building

400 Seventh Street, S.W.

Washington, D.C. 20590

Patricia Ehrlich

Federal Highway Administration

400 Seventh Street, S.W.

Washington, D.C. 20590 
John English

NCUTLO

1776 Massachusetts Avenue, N.W.

Washington, D.C. 20036

Alfred J. Farina, Ph.D.

Problem Behavior Research Division

U.S. Department of Transportation

National Highway Traffic Safety Admin.

Nassif Building

400 Seventh Street, S.W.

Washington, D.C. 20590

Dwight Fee

Chief, Program Education Division

Office of State Program Assistance

U.S. Department of Transportation

National Highway Traffic Safety Admin.

Nassif Building

400 Seventh Street, S.W.

Washington, D.C. 20590

John Fegan

Federal Highway Administration

400 Seventh Street, S.W.

Washington, D.C. 20590

Kenneth Giles

Consumer Products Safety Commission

5401 Westbard Ave.

Bethesda, Maryland

Bennie Hartmann

Supervisor of Pupil Transportation

Howard County Public School System

8045 Route 32

Columbia, Maryland 21044

Michael Hill

Assistant Professor

580 College of Design

Iowa State University

Ames, Iowa 55011

John Jacobus

U.S. Department of Transportation

National Highway Traffic Safety Admin.

Nassif Building

400 Seventh Street, S.W.

Washington, D.C. 20590 
Skip Hood

Coordinator, Pedestrian Program

Bureau of Highway Safety

Carlton Building

Room $\mathbf{5 3 0}$

Tallahassee, Florida 32301

Ralph K. Jones

President

Mid-America Research Institute, Inc.

3720 Lamplighter Drive

Ann Arbor, Michigan 48103

Kent B. Joscelyn, J.D.

Head, Policy Analysis Division

Highway Safety Research Institute

The University of Michigan

2901 Baxter Road

Ann Arbor, Michigan 48109

William M. Kane, Ph.D.

Executive Director

American School of Community Safety Assoc.

1900 Association Drive

Reston, Virginia 22091

Frank Kenel, Ph.D.

American Automobile Association

8111 Gatehouse Road

Falls Church, Virginia 22042

P. Robert Knaff, Ph.D. NRD-40

Director, Office of Driver and

Pedestrian Research

U.S. Department of Transportation

National Highway Traffic Safety Admin.

Nassif Building

400 Seventh Street, S.W.

Washington, D.C. 20590

Richard Knoblauch

Biotechnology Inc.

3027 Rosemary Lane

Falls Church, Virginia 22042

Charito Kruvant

Creative Associates

4419 - 39th Street, N.W.

Washington, D.C. 20016 


\author{
Roger Kurrus \\ U.S. Department of Transportation \\ National Highway Traffic Safety Admin. \\ Nassif Building \\ 400 Seventh Street, S.W. \\ Washington, D.C. 20590 \\ John Lacey \\ Highway Safety Research Center \\ CTP - 197A \\ University of North Carolina \\ Chapel Hill, North Carolina 27514 \\ J.W. Lanum \\ Coordinator, Pedestrian Program \\ D.C. Department' of Transportation \\ Presidential Building \\ 415 - 12th Street, N.W. \\ Room 604 \\ Washington, D.C. 20004 \\ Josh Lehman \\ Office of the Secretary of Transportation \\ 400 Seventh Street, S.W. \\ Washington, D.C. 20590 \\ Marvin M. Levy, Ph.D. \\ U.S. Department of Transportation \\ National Highway Traffic Safety Admin. \\ Nassif Building \\ 400 Seventh Street, S.W. \\ Washington, D.C. 20590 \\ Mary E. Marks, Ph.D. \\ Assistant Research Scientist \\ Policy Analysis Division \\ Highway Safety Research Institute \\ The University of Michigan \\ 2901 Baxter Road \\ Ann Arbor, Michigan 48109 \\ John W. MeNair, J.D. \\ Staff Attorney \\ Mid-America Research Institute, Inc. \\ 3720 Lamplighter Drive \\ Ann Arbor, Michigan 48103
}


Herbert Miller

U.S. Department of Transportation

National Highway Traffic Safety Admin.

Nassif Building

400 Seventh Street, S.W.

Washington, D.C. 20590

Catherine Moran, Executive Director

The Bicycle Federation

Suite 309

1101 - 15th Street, N.W.

Washington, D.C. 20005

Bonita Dostal Neff, Ph.D.

State 4-H Bicycling Coordinator

Michigan State University

175 S. Anthony

East Lansing, Michigan 48824

Lawrence Pavlinski

U.S. Department of Transportation

National Highway Traffic Safety Admin.

Nassif Building

400 Seventh Street, S.W.

Washington, D.C. 20590

Ronald C. Pfefer

Director of Research and Development

Traffic Institute

Northwestern University

555 Clark Street

Evanston, Illinois 60204

Kevin Quinlan

U.S. Department of Transportation

National Highway Traffic Safety Admin.

Nassif Building

400 Seventh Street, S.W.

Washington, D.C. 20590

George Reagle

Director, Office of Driver and

Pedestrian Programs

U.S. Department of Transportation

National Highway Traffic Safety Admin.

Nassif Building

400 Seventh Street, S.W.

Washington, D.C. 20590 
John Robinson, Director

Pedestrian Safety Project

Dade County Department of

Traffic and Transportation

7100 N.W. 36th Street

Miami, Florida 33166

Nancy Rubenson

U.S. Department of Transportation

National Highway Traffic Safety Admin.

Nassif Building

400 Seventh Street, S.W.

Washington, D.C. 20590

Michael F. Smith

U.S. Department of Transportation

National Highway Traffic Safety Admin.

Nassif Building

400 Seventh Street, S.W.

Washington, D.C. 20590

Monroe B. Snyder, Ph.D. NRD-42

Chief, Problem Behavior Research

U.S. Department of Transportation

National Highway Traffic Safety Admin.

Nassif Building

400 Seventh Street, S.W.

Washington, D.C. 20590

Ronald Sostkowski

International Association of

Chiefs of Police

11 Firstfield Road

Gaithersburg, Maryland 20760

David Soule

U.S. Department of Transportation

National Highway Traffic Safety Admin.

Nassif Building

400 Seventh Street, S.W.

Washington, D.C. 20590

Adele Speilberg

U.S. Department of Transportation

National Highway Traffic Safety Admin.

Nassif Building

400 Seventh Street, S.W.

Washington, D.C. 20590 
Paul Steward

State Director of School Transportation

West Virginia Department of Education

1900 Washington Street East

Building \#6, Room B-258

Charleston, West Virginia 25305

Ronald Thompson

Pedestrian/Bicycle Safety Specialist

Room 936

Hill Farms State Office Building

P.O. Box 7910

Madison, Wisconsin 53707

Gary Toth

U.S. Department of Transportation

National Highway Traffic Safety Admin.

Nassif Building

400 Seventh Street, S.W.

Washington, D.C. 20590

Nicholas Tsongos

U.S. Department of Transportation

National Highway Traffic Safety Admin.

Nassif Building

400 Seventh Street, S.W.

Washington, D.C. 20590

Rudolph Umbs

Federal Highway Administration

400 Seventh Street, S.W.

Washington, D.C. 20590

William C. Wheeler, Jr., Esquire NRD-42

U.S. Department of Transportation

National Highway Traffic Safety Admin.

Nassif Building

400 Seventh Street, S.W.

Washington, D.C. 20590

John R. Wilhelm, DPA

Marketing Communications

Orlando Division/Martin Marietta

P.O. Box 5837 MP-52

Orlando, Florida 32805 
William Wilkinson

Bicycle Manufacturers Assoc.

1101 - 15th Street, N.W.

Washington, D.C. 20005

Allan Williams, Ph.D.

Insurance Institute for Highway Safety

Watergate 600

Washington, D.C. 20037

Curtis Winston

Office of Highway Safety

State of New Jersey

$\mathrm{CN}-048$

Trenton, New Jersey 08618

Leslie Woolf

U.S. Department of Transportation

National Highway Traffic Safety Admin.

Nassif Building

400 Seventh Street, S.W.

Washington, D.C. 20590

Barbara Wright, Ph.D.

Director

Ohio Traffic Safety Education Center

National Center for Research in

Vocational Education

Ohio State University

1960 Kenny Road

Columbus, Ohio 43210 



\section{BIBLIOGRAPHY}

U.S. Department of Transportation. 1979. Proposed plan for highway safety research, development, and demonstration (section 403 of title, USC): Fiscal years 1980-1984. National Highway Traffic Safety Administration. 
